\title{
Presynaptic G-Protein-Coupled Receptors Dynamically Modify Vesicle Fusion, Synaptic Cleft Glutamate Concentrations, and Motor Behavior
}

\author{
Tatyana Gerachshenko, ${ }^{\star}$ Eric Schwartz ${ }^{\star}$ Adam Bleckert, Huzefa Photowala, Andrew Seymour, and Simon Alford \\ Department of Biological Sciences, University of Illinois at Chicago, Chicago, Illinois 60607
}

\begin{abstract}
Understanding how neuromodulators regulate behavior requires investigating their effects on functional neural systems, but also their underlying cellular mechanisms. Utilizing extensively characterized lamprey motor circuits, and the unique access to reticulospinal presynaptic terminals in the intact spinal cord that initiate these behaviors, we investigated effects of presynaptic G-protein-coupled receptors on locomotion from the systems level, to the molecular control of vesicle fusion. 5-HT inhibits neurotransmitter release via a G $\beta \gamma$ interaction with the soluble $N$-ethylmaleimide-sensitive factor attachment protein receptor (SNARE) complex that promotes kissand-run vesicle fusion. In the lamprey spinal cord, we demonstrate that, although presynaptic 5-HT receptors inhibit evoked neurotransmitter release from reticulospinal command neurons, their activation does not abolish locomotion but rather modulates locomotor rhythms. Liberation of presynaptic $\mathrm{G} \beta \gamma$ causes substantial inhibition of AMPA receptor-mediated synaptic responses but leaves NMDA receptor-mediated components of neurotransmission mostly intact. Because $\mathrm{G} \beta \gamma$ binding to the SNARE complex is displaced by $\mathrm{Ca}^{2+}$ synaptotagmin binding, 5 -HT-mediated inhibition displays $\mathrm{Ca}^{2+}$ sensitivity. We show that, as $\mathrm{Ca}^{2+}$ accumulates presynaptically during physiological bouts of activity, 5-HT/G $\beta \gamma$-mediated presynaptic inhibition is relieved, leading to a frequency-dependent increase in synaptic concentrations of glutamate. This frequency-dependent phenomenon mirrors a shift in the vesicle fusion mode and a recovery of AMPA receptor-mediated EPSCs from inhibition without a modification of NMDA receptor EPSCs. We conclude that activation of presynaptic 5-HT G-protein-coupled receptors state-dependently alters vesicle fusion properties to shift the weight of NMDA versus AMPA receptor-mediated responses at excitatory synapses. We have therefore identified a novel mechanism in which modification of vesicle fusion modes may profoundly alter locomotor behavior.
\end{abstract}

\section{Introduction}

Vertebrate locomotion mediated by spinal central pattern generators (CPGs) is initiated by excitation of brainstem reticulospinal nuclei (supplemental Fig. 1, available at www.jneurosci.org as supplemental material) (Shik et al., 1969; Grillner and Shik, 1973; Dubuc et al., 2008). 5-HT modulates, and may excite, spinal CPGs after traumatic or experimental loss of this output (Brustein and Rossignol, 1999). However, 5-HT also potently inhibits this descending excitation (Buchanan and Grillner, 1991) by acting at presynaptic $5 \mathrm{HT}_{1 \mathrm{~B}}$ receptors both on reticulospinal axon terminals and on intraspinal excitatory interneurons (EINs) (Parker and Grillner, 1999; Schwartz et al., 2005). Postsynaptically, sero-

Received March 24, 2009; revised May 20, 2009; accepted June 26, 2009.

This work was supported by National Institute of Neurological Disorders and Stroke Grant R01 NS052699 (S.A.). We thank Heidi Hamm, Edaeni Hamid, and Réjean Dubuc for their helpful discussion of the experiments and critical reading of this manuscript.

*T.G. and E.S. contributed equally to this work.

Correspondence should be addressed to Simon Alford, Department of Biological Sciences, University of Illinois at Chicago, 840 West Taylor Street, Chicago, IL 60607. E-mail: sta@uic.edu.

E. Schwartz's present address: Department of Biology, Ecole Normale Superieur, 46 rue d'Ulm, 75005 Paris, France.

A. Bleckert's present address: Graduate Program in Neurobiology and Behavior, Box 357270, T-471 Health Sciences Center, Seattle, WA 98195-7270.

D0I:10.1523/JNEUROSCI.1404-09.2009

Copyright $\odot 2009$ Society for Neuroscience $\quad 0270-6474 / 09 / 2910221-13 \$ 15.00 / 0$ tonin potentiates spike frequencies by inhibiting late afterhyperpolarizations and generating plateau potentials (Hounsgaard and Kiehn, 1989; Wallén et al., 1989; Zhong et al., 2006). 5-HT projections also evoke locomotion (Liu and Jordan, 2005; Jordan et al., 2008), by plateau potential activation (Perrier and DelgadoLezama, 2005), and 5-HT receptors contribute to sustained, ventral root bursting (Harris-Warrick and Cohen, 1985; Hounsgaard and Kiehn, 1989; Parker and Grillner, 1999; Kozlov et al., 2001; Schwartz et al., 2005; Biró et al., 2006).

Vertebrate serotonergic projections form diffuse paracrine terminals that innervate extrasynaptically (Schotland et al., 1995) and 5-HT prolongs bursts evoked by spinal application of glutamatergic agonists (Harris-Warrick and Cohen, 1985; Christenson et al., 1989). However, this artificial CPG activation bypasses reticulospinal neurons, which drive locomotion in intact organisms-a synaptic connection strongly depressed by 5-HT (Buchanan and Grillner, 1991; Parker and Grillner, 1999). Thus, it remains undetermined whether 5-HT can modify physiologically relevant brainstem-initiated locomotion given its powerful presynaptic inhibitory effects.

At lamprey reticulospinal axons, 5-HT does not modify release probability, but liberates presynaptic $G \beta \gamma$, to compete with $\mathrm{Ca}^{2+}$-dependent synaptotagmin binding to soluble $N$-ethylmaleimide-sensitive factor attachment protein receptor (SNARE) complexes (Blackmer et al., 2001, 2005; Gerachshenko et al., 
2005). This reduces synaptic cleft glutamate concentrations (Schwartz et al., 2007) by causing kiss-and-run fusion (Photowala et al., 2006). Thus, at high $\left[\mathrm{Ca}^{2+}\right]$, preferential synaptotagmin binding to SNARE complexes occludes 5-HT receptor-mediated inhibition (Yoon et al., 2007). Lower synaptic glutamate concentrations cause AMPA receptor EPSCs to be more profoundly inhibited than NMDA receptor EPSCs (Schwartz et al., 2007). Although kiss-and-run fusion is seen at synapses (Zhang et al., 2009) and endocrine cells (Elhamdani et al., 2006), behavioral roles for this phenomenon remain unexplored. At synapses, it has been proposed that kiss-and-run fusion minimizes metabolic losses required for lipid and protein resorting, but also that fusion modes influence neurotransmitter secretion (Choi et al., 2003). It has been proposed that kiss-and-run fusion is $\mathrm{Ca}^{2+}$ dependent and is modified by high-frequency stimulation (Harata et al., 2006; Zhang et al., 2009).

We demonstrate the outcome of presynaptic $5-\mathrm{HT}_{1 \mathrm{~B} / 1 \mathrm{D}}$ receptor activation on neurotransmission during physiological activity and behavior-brainstem-evoked locomotion. Both the target of 5-HT liberated G $\beta \gamma$ at the SNARE complex and the effects of $G \beta \gamma$ on vesicle fusion are necessary to maintain the modulatory role of 5-HT in the spinal cord. If, in contrast, 5-HT merely inhibited neurotransmitter release, no descending excitation would remain, no locomotion would occur, and other spinal modulatory effects of 5-HT would be moot in behaving vertebrates.

\section{Materials and Methods}

Experiments were performed on the isolated spinal cords or spinal cords and brainstems of larval lampreys (Petromyzon marinus). The animals were anesthetized with MS-222 (tricaine methanesulfonate) (100 mg/L; Sigma-Aldrich), killed by destruction of thalamus and basal ganglia, and dissected in a cold saline solution (Ringer's) of the following composition (in mM): $100 \mathrm{NaCl}, 2.1 \mathrm{KCl}, 2.6 \mathrm{CaCl}_{2}, 1.8 \mathrm{MgCl}_{2}, 4$ glucose, 5 HEPES, adjusted to a $\mathrm{pH}$ of 7.60 . Procedures conformed to institutional guidelines (University of Illinois at Chicago Animal Care Committee). Significance was determined using Student's $t$ tests of means. Errors are expressed as SEM.

Electrophysiology. Somata and axons of reticulospinal neurons were recorded with conventional sharp microelectrodes containing 1-3 M $\mathrm{KCl}$. For those experiments in which EGTA was injected into the presynaptic terminal, the electrode contained $1 \mathrm{M} \mathrm{KCl}, 100 \mathrm{~mm}$ EGTA, $5 \mathrm{~mm}$ HEPES, $\mathrm{pH}$ adjusted to 7.2 with $\mathrm{KOH}$. Electrode impedances ranged from 20 to $50 \mathrm{M} \Omega$. EGTA was applied to the interior of the recorded axon by pressure ejection from the microelectrode. Postsynaptic neurons were recorded within the spinal ventral horn. These neurons are principally interneurons of the spinal CPG because most reticulospinal output is directed to these interneurons. Reticulospinal projections to motoneurons are principally polysynaptic (Zelenin et al., 2001). Patch electrodes for whole-cell postsynaptic recordings contained the following (in $\mathrm{mM}$ ): 102.5 cesium methane sulfonate, $1 \mathrm{NaCl}, 1 \mathrm{MgCl}_{2}, 5$ EGTA, 5 HEPES, pH adjusted to 7.2 with $\mathrm{CsOH}$. Ventral root recordings were made with cut and polished glass micropipettes with tip diameters of $30-100 \mu \mathrm{m}$ and filled with Ringer's solution. These were placed over the ventral roots and recorded using conventional AC amplifiers. Locomotion was evoked by placing a pipette (tip diameter, $\sim 1 \mu \mathrm{m}$ ) into the mesencephalic locomotor region (MLR) and pressure injecting glutamate (1 mM in pipette; volume per injection was $\sim 100 \mathrm{nl}$ ).

To determine the sum of ventral root output during the MLR-evoked burst of fictive locomotion, the absolute value of ventral root output from left and right ventral root pairs was summed. These data were then integrated to represent the cumulative work done. Area under noise was subtracted by fitting a straight line to the initial slope of the integral curve (before application of glutamate to the brainstem) and subtracting that line from the total integral. The responses shown in Figure 2 are measures of the cumulative ventral root total output.
Imaging. Confocal imaging was performed using a modified Bio-Rad MRC 600 confocal microscope using a $488 \mathrm{~nm}$ argon ion laser for excitation. Intensity was controlled by an acousto-optical tunable filter on the laser fiber optic launch. The photomultiplier outputs were amplified with low noise current amplifiers (Stanford Instruments) and digitized to 12 bits with a National Instruments board and custom software written under Matlab (Mathworks). The scan head mirrors were driven through the MRC 600 scan head amplifiers with the same custom software. This software is available on our website (http://alford.bios.uic.edu).

Application of FM dye. FM1-43 (5 $\mu \mathrm{M})$ was applied as a stream from a small pipette placed over the surface of the spinal cord. Constant flow was ensured by a syringe pump. One thousand stimuli were applied to a microelectrode recorded axon during the dye application while the presence of the dye in the tissue surrounding the axons was confirmed by imaging. Dye application was subsequently terminated. During this staining protocol, postsynaptic activity was blocked with glutamate receptor antagonists CNQX and AP5 (5 and $100 \mu \mathrm{M}$, respectively). Excess dye was removed with Advasep 7 (Kay et al., 1999) (1 mM, 1 min; Cydex) to reveal areas of stimulus-dependent staining.

Labeling of reticulospinal axons with $\mathrm{Ca}^{2+}$-sensitive dye. Reticulospinal axons were filled with $\mathrm{Ca}^{2+}$-sensitive dye by pressure injection $\left(\mathrm{Ca}^{2+}\right.$ sensitive dye; Fluo 5F; 5 mm in microelectrode; Invitrogen). Line scan imaging was performed by tracking the confocal scan mirrors along the axon plasma membrane at $500 \mathrm{~Hz}$.

Calibration of the $\mathrm{Ca}^{2+}$-sensitive dyes. The dye sensitivity to $\mathrm{Ca}^{2+}$ was determined using the same optical path (confocal microscope) that was used to measure $\mathrm{Ca}^{2+}$ transients in the tissue. Dyes $(5 \mu \mathrm{M})$ were prepared in blends of two $\mathrm{Ca}^{2+}$ buffer standards $\left[10 \mathrm{~mm} \mathrm{~K}{ }_{2}\right.$ EGTA, $100 \mathrm{~mm} \mathrm{KCl}$, and $30 \mathrm{~mm}$ 3-( $N$-morpholino)-propanesulfonic acid (MOPS); and 10 mM Ca-EGTA, $100 \mathrm{~mm} \mathrm{KCl}$, and $30 \mathrm{~mm}$ MOPS] both at pH 7.2 (Invitrogen) to make an 11 point standard curve. The dye buffer mix was placed between coverslips cooled from below with a liquid cooling system to $10^{\circ} \mathrm{C}$ and imaged from above with the $100 \times$ water-immersion lens over the upper coverslip. It is important to note that both the need to calibrate the dyes outside the cell and that high temporal and spatial resolution cannot be followed during action potentials mean that peak $\mathrm{Ca}^{2+}$ measurements cannot represent the absolute $\mathrm{Ca}^{2+}$ concentration necessary to evoke neurotransmitter release or to modify it. However, our calibrations are sufficient to ensure that the measured intensity values do not represent saturation of the dye at the time of measurement.

\section{Results}

\section{5-HT and MLR-induced locomotion}

5-HT profoundly inhibits excitatory neurotransmission both from descending reticulospinal neurons (Buchanan and Grillner, 1991) and intraspinal EINs (Parker and Grillner, 1999) (for their role in the circuitry of the CPG, see supplemental Fig. 1, available at www.jneurosci.org as supplemental material). This presynaptic inhibition appears incompatible with the modulatory effect of 5-HT on locomotion during brainstem-initiated locomotion, because it would prevent descending command activation of the spinal motor system. Consequently, we determined whether locomotion initiated by brainstem stimulation could be activated when 5-HT was superfused over the spinal cord.

Locomotion was initiated in a brain-spinal cord preparation by glutamate microinjected into the MLR. Experimental effects of spinal 5-HT receptor activation were determined by selectively applying 5-HT and 5- $\mathrm{HT}_{1 \mathrm{~B} / 1 \mathrm{D}}$ receptor agonists to the spinal cord isolated from the brain using a split-bath (Fig. $1 A$ ), with a barrier between the brain and the spinal cord placed at approximately spinal segments $2-5$. Microinjection of L-glutamate ( $1 \mathrm{mM} ; 100$ $\mathrm{nl}$ ) into the MLR (Fig. $1 \mathrm{~A}$ ) reproducibly induced fictive locomotor activity, monitored using a pair of extracellular electrodes placed over contralaterally opposed pairs of ventral roots, as well as by intracellular recordings from reticulospinal neurons in the middle rhombencephalic reticular nucleus (MRRN). After the 

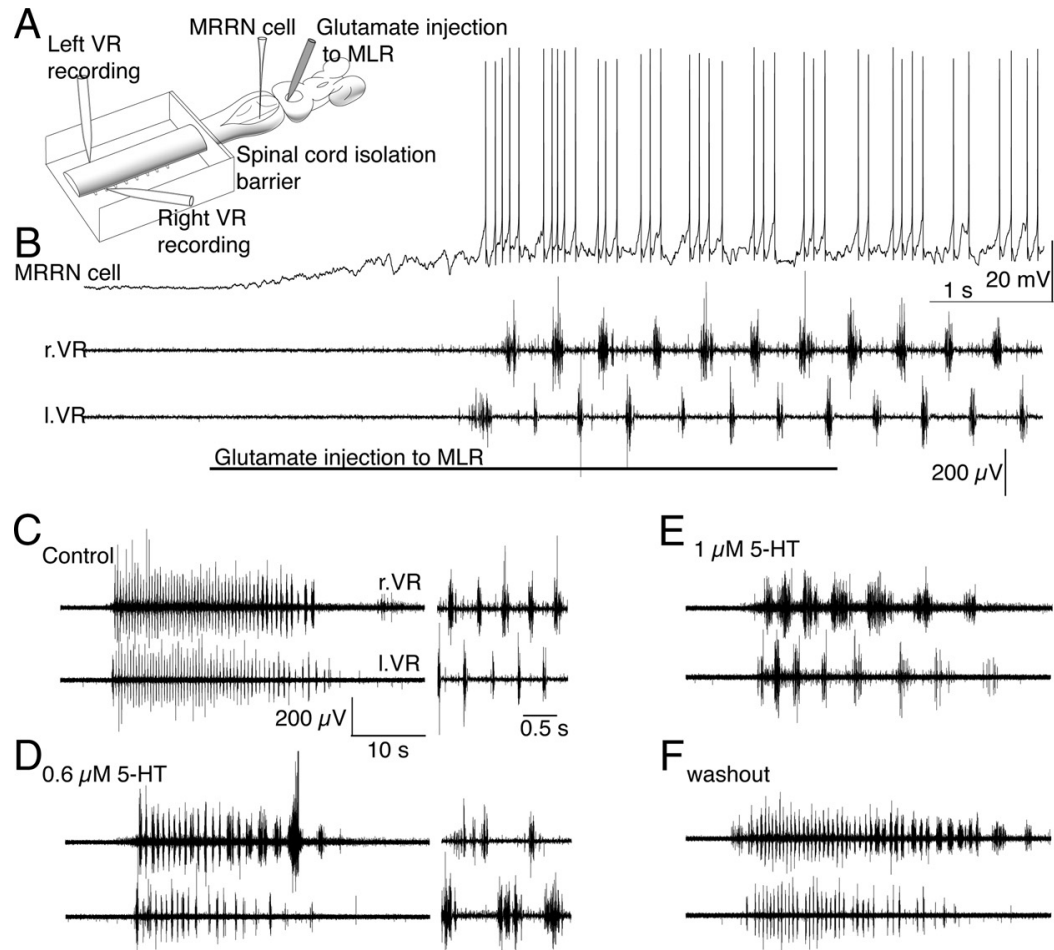

$\mathrm{E}_{1 \mu \mathrm{M} 5-\mathrm{HT}}$

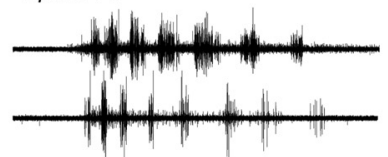

$\mathrm{F}$

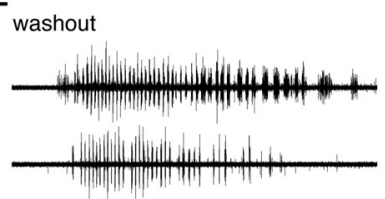

G
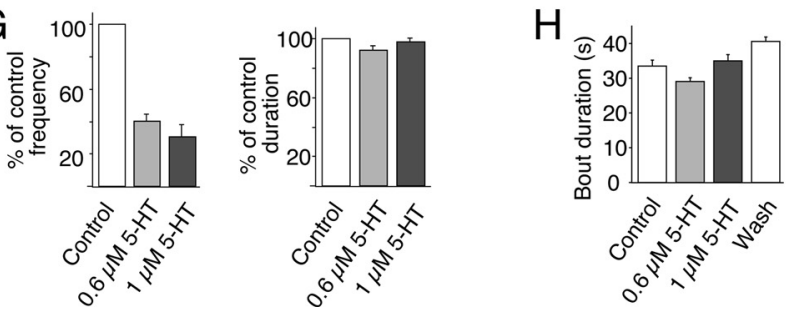

Figure 1. 5-HT reduces the cycle frequency of brainstem-evoked locomotion. $\boldsymbol{A}$, Recording arrangement to evaluate effects of spinal agonist/antagonist application on brainstem-evoked fictive locomotion. The spinal cord was pharmacologically isolated from the brainstem with a barrier to superfusate flow at the second to fifth spinal segment. Glutamate (1 mm) was microinjected into the MLR from a pipette (1-2 $\mu \mathrm{m}$ diameter tip). MRRN neurons were recorded intracellularly and fictive locomotion with suction electrodes over left and right pairs of spinal ventral roots (I.VR, r.VR). $\boldsymbol{B}$, Five second injection of L-glutamate into the MLR evokes depolarization and rhythmic firing of the MRRN neuron and alternating ventral root activity. $\boldsymbol{C}$, Similar control fictive locomotion to $B$ recorded in a pair of ventral roots and activated by $5 \mathrm{~s}$ glutamate microinjection to the MLR. The entire duration of the fictive swimming bout is shown along with activity from the bout in extended time base to show the frequency of alternating activity (inset right). D, 5-HT $(0.6 \mu \mathrm{m})$ superfused over the spinal cord reduced fictive locomotion cycle frequencies with no modification of the bout duration. Inset, Time base-expanded activity. $\boldsymbol{E}, 5-\mathrm{HT}(1 \mu \mathrm{M})$ further reduced cycle frequencies but had no effect on total bout duration. $\boldsymbol{F}$, Wash of 5-HT from the spinal compartment allowed recovery of the cycle frequency. $\mathbf{G}$, Mean effects of 5-HT on fictive locomotor bout duration and cycle frequency on all preparations tested. Data were normalized to control values before 5-HT application. 5-HT reduced cycle frequencies but left bout durations unchanged. $\boldsymbol{H}$, Mean effects over three sequential glutamate injections from which examples were taken $(\boldsymbol{C}-\boldsymbol{F})$ of 0.6 and $1 \mu \mathrm{m} 5-\mathrm{HT}$ on total bout duration (start to end of fictive swim) and cycle frequency compared with control and wash of 5-HT. Error bars indicate SEM.

transient glutamatergic stimulation of the MLR, repetitive bursting of reticulospinal neurons coincided with fictive locomotion recorded as alternating activity in the ventral roots, in which reticulospinal neurons fire in phase with activity recorded from ventral roots of the ipsilateral rostral spinal cord (Fig. $1 B$ ) (Kasicki et al., 1989; Sirota et al., 2000; Dubuc et al., 2008).

5 -HT, applied selectively to the spinal cord at doses that inhibit reticulospinal EPSCs by $50-80 \%(0.6-1 \mu \mathrm{M})$ (Schwartz et al., 2007), dose-dependently reduced ventral root cycle frequency during brainstem-evoked fictive locomotion (Fig. $1 C-F$ ) precisely as has been reported for fictive locomotion evoked by exogenous amino acids superfused over the isolated spinal cord (Harris-Warrick and Cohen, 1985; Wallén et al., 1989). At $0.6 \mu \mathrm{M}$

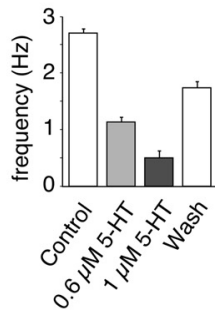

5-HT, cycle frequency was significantly reduced (Fig. $1 D$ ) to $40.1 \pm 4.5 \%$ of the control frequency (Fig. $1 G)(n=5$ preparations; $p<0.01$ ) and at $1 \mu \mathrm{M} 5$-HT (Fig. $1 E)$ to $30.5 \pm 9.8 \%$ of control $(n=4$ preparations) (Fig. $1 G)(p<0.01)$. Total duration of each locomotor bout was not significantly altered (Fig. 1C-F) $(92 \pm 3 \%$ of control at $0.6 \mu \mathrm{M} 5-\mathrm{HT}$ and $98 \pm 3 \%$ of control at $1 \mu \mathrm{M}$ ) (Fig. $1 G$ ). After wash of 5-HT from the spinal compartment, locomotor activity recovered close to control cycle frequencies while locomotor bout durations remained stable (Fig. 1C-G). Thus, the presynaptic action of $5-\mathrm{HT}$ is more complex than a powerful inhibition of descending excitatory drive to the spinal CPG because such an effect would be expected to abolish MLR-evoked fictive locomotion. Moreover, it is unlikely that 5-HT only acts at a subset of reticulospinal neurons as we have recorded from hundreds of reticulospinal/spinal neuron pairs but never found a response not inhibited by 5 -HT.

The effect of 5-HT on locomotion was reproducible as were bouts of evoked locomotion. Fictive locomotor bouts were of consistent duration and cycle frequency when initiated in sequential glutamate microinjections to the MLR, at 5 min intervals in both control and during application of 5-HT (Fig. $1 \mathrm{H}$ ) (mean control cycle frequency over three sequential glutamate microinjections in the example preparation shown in Fig. 1 was $2.7 \pm 0.1$ $\mathrm{Hz}$; mean control burst duration was $33.5 \pm 1.7 \mathrm{~s}$ ). In control experiments, with no drug in the spinal compartment, the mean cycle frequency from all seven preparations was $1.5 \pm 0.20 \mathrm{~Hz}$ and mean bout duration after each glutamate injection was $35.9 \pm 2.5$ s. Thus, 5 -HT at 0.6 and 1.0 $\mu \mathrm{M}$ left bout duration unchanged but reduced the cycle frequency (Fig. $1 H$ ).

Although 5-HT did not prevent fictive locomotion, it is possible that it reduced locomotor cycle frequencies simply by reducing CPG activity after a loss of excitatory output from the reticulospinal system. If descending excitation were reduced, the total output of the spinal CPG would also be reduced. This CPG output may be calculated as a sum of the combination of the cycle frequency, the number of ventral root spikes, and the amplitude of spikes as larger higher threshold neurons contribute more to the signal than smaller lower threshold neurons. To quantify whether 5-HT did alter total ventral root output power during bouts of locomotion, we rectified and then summed left and right ventral root activity and calculated the integral of this activity for the duration of the MLR-evoked locomotor bout. This summed activity represents an integration of frequency and event amplitude; thus, larger more readily recorded spikes will contribute more than smaller units. Three sequential evoked bouts in each of control 
and in 5-HT were recorded in each preparation. Output power calculated in this way was then normalized to the maximum at the end of control locomotor bouts in each preparation (Fig. 2 A). At 0.6 $\mu \mathrm{M}, 5-\mathrm{HT}$ left the mean normalized output power unchanged throughout the bout (107 $\pm 20 \%$ of control) (Fig. $2 B$ ). Even at $1 \mu \mathrm{M}$ 5-HT, which reduces EPSCs to $20 \%$ of control (Takahashi et al., 2001), output power remained at $75 \pm 14 \%$ of control (Fig. $2 C)(n=5)$. Thus, although 5-HT substantially reduced locomotor frequency, it had little effect on total ventral root output evoked by MLR stimulation. Instead, the same total output was contained within longer bursts on each side of the spinal cord.

\section{The effect of 5-HT is mimicked by selective activation of $5-\mathrm{HT}_{1 \mathrm{~B} / 1 \mathrm{D}}$ receptors}

There is substantial uncertainty over the physiological target of 5-HT that leads to modification of locomotion. Fictive locomotion in the isolated lamprey spinal cord can be evoked by application of exogenous glutamate agonists or uptake inhibitors (typically NMDA or D-glutamate) (Brodin et al., 1985). In the isolated spinal cord, fictive locomotion evoked by application of exogenous amino acid agonists is slowed by presynaptic $5-\mathrm{HT}_{1 \mathrm{~B} / 1 \mathrm{D}}$ receptors (Schwartz et al., 2005) similar to the effect of 5-HT itself (Harris-Warrick and Cohen, 1985). To assay directly whether inhibition of synaptic transmission by presynaptic 5-HT receptors is sufficient to alter locomotion, we repeated the brainstem-evoked locomotion experiments described above but substituted 5-HT with 2-[5-[3-(4-methylsulfonylamino)benzyl1,2,4-oxadiazol-5-yl]-1 $H$-indol-3-yl] ethanamine (L694-247), a selective $5-\mathrm{HT}_{1 \mathrm{~B} / 1 \mathrm{D}}$ agonist. $5-\mathrm{HT}_{1 \mathrm{~B}}$ and $5-\mathrm{HT}_{1 \mathrm{D}}$ receptors are not well resolved pharmacologically and share very similar sequences in mammals (Doménech et al., 1997); however, similar to mammals, in lamprey L694-247 acts selectively at presynaptic loci to inhibit EPSCs without postsynaptically altering afterhyperpolarizations, membrane potential, input impedance, or spike frequencies of spinal neurons (Schwartz et al., 2005). Locomotor activity was again initiated by glutamate microinjection into the MLR, and ventral root activity recorded from contralateral pairs of ventral roots. Selective activation of $5-\mathrm{HT}_{1 \mathrm{~B} / 1 \mathrm{D}}$ receptors in the pharmacologically isolated spinal compartment with L694-247 mimicked the effect of 5-HT; reducing the cycle frequency while leaving the duration of the locomotor bout unchanged (cycle frequency reduced to $42.6 \pm 13.5 \%$ of control at $0.1 \mu \mathrm{M}, p \leq 0.05$; and $27.4 \pm 4.9 \%$ at $0.2 \mu \mathrm{M}, p<0.05 ; n=4)$ (Fig. $3 A, B, D$ ) (bout durations were $94.1 \pm 3.0$ and $117.0 \pm 9.0 \%$ of control at 0.1 and $0.2 \mu \mathrm{M}$ L694-247, respectively) (Fig. 3E). Thus, activation of presynaptic $5-\mathrm{HT}_{1 \mathrm{~B} / 1 \mathrm{D}}$ receptors reproduces the effect of 5-HT (Harris-Warrick and Cohen, 1985) on both exogenous amino acid (Schwartz et al., 2005) and brainstemevoked locomotion (Fig. 3B).

\section{Reducing synaptic strength does not mimic 5-HT-mediated decreases of locomotor cycle frequency}

As for experiments in which 5-HT was applied, it is possible that $5-\mathrm{HT}_{1 \mathrm{~B} / \mathrm{1D}}$ receptors slow fictive locomotion simply by reducing synaptic drive to the $\mathrm{CPG}$. If 5- $\mathrm{HT}_{1 \mathrm{~B} / 1 \mathrm{D}}$ receptors acted by reducing neurotransmitter release probability, then a uniform aver-

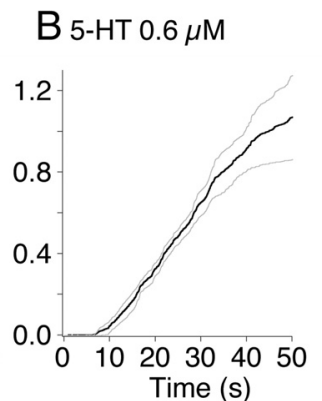

$\mathrm{C}_{5-\mathrm{HT}} 1 \mu \mathrm{M}$

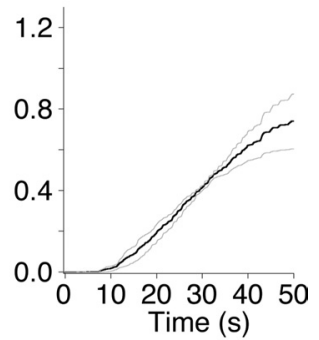

Figure 2. 5-HT does not significantly alter ventral root output power. $\boldsymbol{A}$, Summed normalized absolute ventral root activity is 作 $107 \pm 20 \%$ of control. $C$, The effect of $5-\mathrm{HT}(1 \mu \mathrm{M})$. Output power remained at $75 \pm 14 \%$ of control. Data were

aged loss of postsynaptic response would be the outcome over the many synapses responsible for activation of fictive locomotion in the spinal cord. We wanted to mimic a hypothetical reduction in excitatory drive to contrast such an effect with that of $5-\mathrm{HT}_{1 \mathrm{~B} / 1 \mathrm{D}}$ receptor activation. However, it is not possible to selectively reduce glutamate release probability without altering all synaptic transmission within the spinal motor circuitry. Nevertheless, it is possible to uniformly reduce postsynaptic glutamate receptor activation by applying a nonselective ionotropic glutamate receptor antagonist. For these experiments, we investigated the effect of merely halving spinal EPSP amplitudes using the glutamate receptor antagonist kynurenate to mimic the effects of a simple reduction in excitatory neurotransmission - what would happen if glutamate release probability at spinal synapses was uniformly reduced rather than the more complex effects of $5-\mathrm{HT}_{1 \mathrm{~B} / 1 \mathrm{D}}$ receptors that we previously demonstrated (Photowala et al., 2006; Schwartz et al., 2007). If 5- $\mathrm{HT}_{1 \mathrm{~B} / 1 \mathrm{D}}$ receptors merely inhibit both descending reticulospinal and intraspinal glutamatergic synaptic excitation, kynurenate would postsynaptically mimic the distribution of the presynaptic inhibitory effects of 5-HT. The extent of $5-\mathrm{HT}_{1 \mathrm{~B} / 1 \mathrm{D}}$ receptor-mediated inhibition of individual evoked EPSCs using $0.1 \mu \mathrm{M} \mathrm{L694-247} \mathrm{is} \mathrm{similar} \mathrm{to} \mathrm{that} \mathrm{of} 200 \mu \mathrm{M}$ kynurenate (Fig. $3 F-H$ ). However, in contrast to the effect of L694-247, kynurenate abolished MLR-evoked fictive locomotion (200 $\mu$ m; $n=4$ of 4 preparations) (Fig. $3 C$ ). Thus, reducing synaptic transmission by just $50 \%$ has a dramatically and qualitatively different effect than activation of 5- $\mathrm{HT}_{1 \mathrm{~B} / 1 \mathrm{D}}$ receptors. Indeed, it is also apparent that, unlike the activation of presynaptic 5-HT receptors, reducing reticulospinal output by lowering MLR activation correspondingly reduces electromyographic activity in semiintact preparations of lamprey (Sirota et al., 2000).

The effect of presynaptic 5-HT receptor activation is paradoxical in that 5-HT inhibits output from the brainstem but its effect on locomotion does not resemble either reducing brainstem drive to the CPG or generally inhibiting spinal excitatory activity. It has been suggested (Biró et al., 2006) and contradicted (Parker and Grillner, 1999) that 5-HT can reduce spinal inhibitory synaptic transmission. In fact, 5-HT may actually enhance spinal inhibitory synaptic transmission (Parker and Grillner, 1999). However, these effects were observed at 10- to 30-fold higher 5-HT concentrations than in this study. For comparison, during paired recordings between reticulospinal axons and postsynaptic neurons, 5-HT $(0.6 \mu \mathrm{M})$ or L694-247 $(0.1 \mu \mathrm{M})$ inhibited EPSCs by $55 \pm 7 \%(n=22)$ and $63 \pm 16 \%(n=3)$ (Fig. $3 F, G$ ); neither prevented fictive locomotion. Kynurenate 
A Control
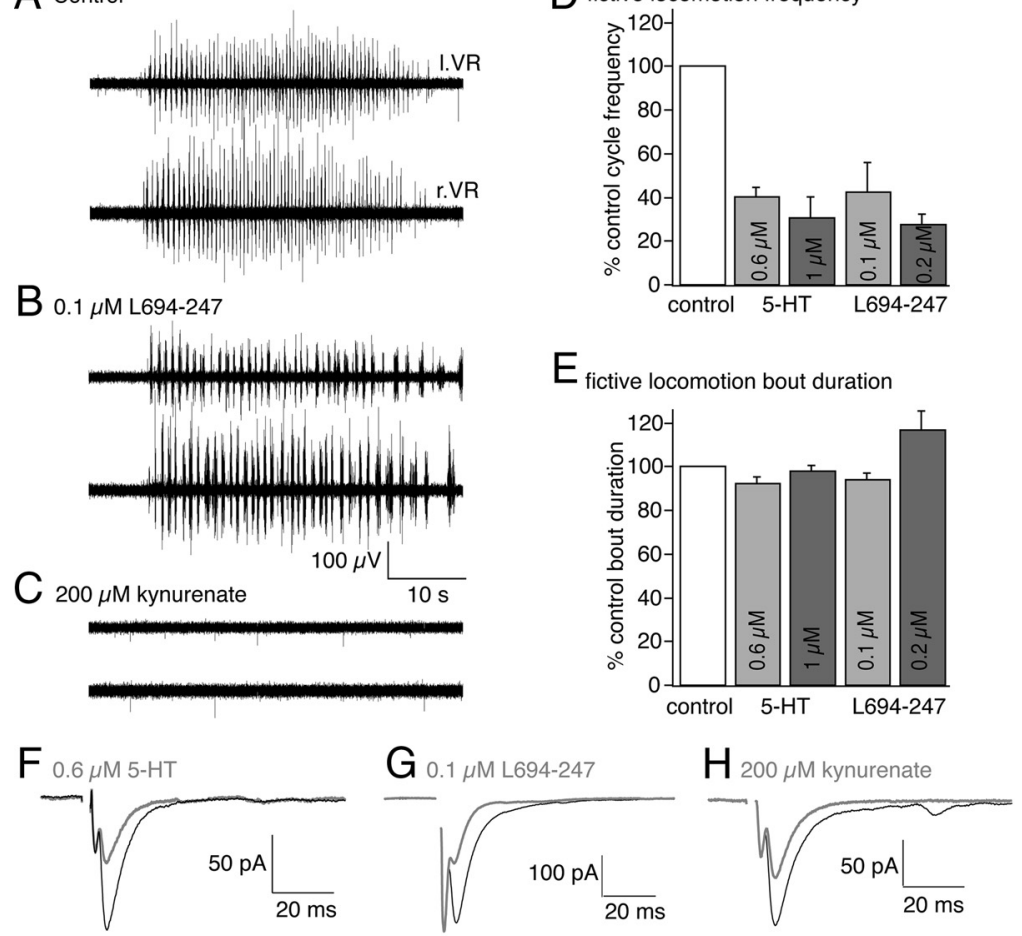

I Sum of ventral root output

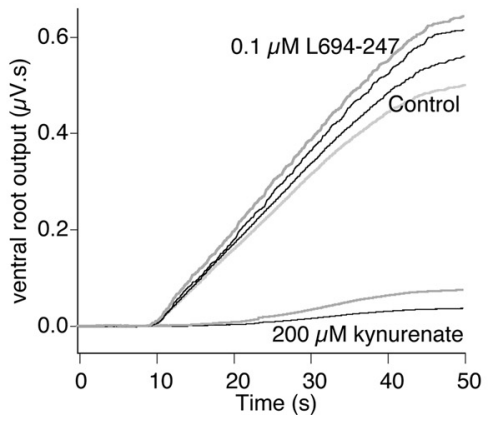

$\checkmark$ Normalized ventral root output

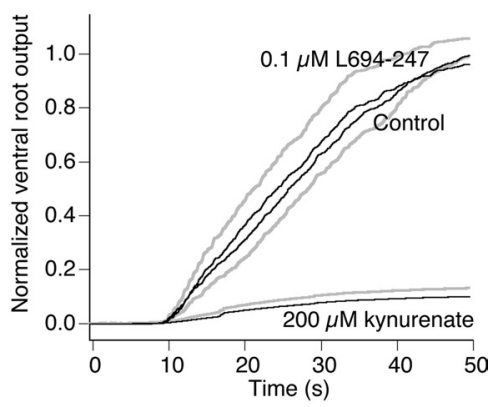

Figure 3. $5-\mathrm{HT}_{1 \mathrm{~B} / 1 \mathrm{D}}$ receptors reduce brainstem-activated $\mathrm{CPG}$ cycle frequency. A, Fictive locomotion was activated by glutamate microinjection to the MLR as for Figure 1 and recorded from pairs of ventral roots in the spinal cord. $B$, Application of the $5-\mathrm{HT}_{1 \mathrm{~B} / 1 \mathrm{D}}$ receptor agonist $\mathrm{L694-247}(0.1 \mu \mathrm{m})$ to the spinal cord compartment reduced the locomotor cycle frequency but did not alter the total bout duration. C, Application of kynurenate $(200 \mu \mathrm{m})$ to the spinal cord compartment abolished ventral root activity from the spinal cord in response to glutamate microinjection to the MLR. D. Data normalized from all preparations to show mean effects of 5-HT (from Fig. 1) and L694-247 on spinal fictive locomotion cycle frequency. Both reduced the frequency dose-dependently. $\boldsymbol{E}$, In contrast, neither 5-HT nor L694-247 modified the total bout duration after glutamate microinjection to the MLR. Error bars indicate SEM. $\boldsymbol{F}-\boldsymbol{H}, \mathrm{A}$ comparison of the effects of 5-HT $(0.6 \mu \mathrm{M}), \mathrm{L} 694-247(0.1 \mu \mathrm{M})$, and kynurenate $(200 \mu \mathrm{M})$ on synaptic transmission (gray compared with black controls) mediated between paired reticulospinal axons and postsynaptic ventral horn neurons stimulated every $15 \mathrm{~s}$. These agonists at these doses gave rather similar inhibitory effects on EPSCS. I, Summed absolute ventral root activity (microvolts - second) is plotted against time during the MLR evoked fictive locomotion bout. Activity was measured in three sequential locomotor bouts activated at 5 min intervals in control, in L694-247 $(0.1 \mu \mathrm{M})$ and kynurenate $(200 \mu \mathrm{m})$ for the preparation shown in $\boldsymbol{A}-\boldsymbol{C}$ (black, mean of 3 bouts; gray, SEM for L694-247 above the mean trace and for control below the mean trace; for kynurenate SEM, gray trace above the mean trace in black). J, Normalized summed ventral root activity from all preparations $(n=5)$ in which L694-247 (0.1 $\mu \mathrm{M})$ was applied (black shows mean of all preparations, SEM in gray, similarly to I).

$(200 \mu \mathrm{M})$, in contrast, reduced EPSCs by $52 \pm 5 \%(n=4)$ (Fig. $3 \mathrm{H}$ ) yet prevented fictive locomotion. We conclude that the effect of 5-HT on excitatory synaptic transmission is different from a simple reduction in $P_{\mathrm{r}}$.

As for the effect of 5-HT, we quantified whether selective activation of presynaptic $5-\mathrm{HT}_{1 \mathrm{~B} / 1 \mathrm{D}}$ receptors reduced total ventral root output power during locomotion. We again rectified and then summed left and right ventral root activity and calculated the integral of this activity for the duration of the MLRevoked locomotor bout. Three sequential evoked bouts in each of control, L694-247 $(0.1 \mu \mathrm{M})$, and kynurenate $(200 \mu \mathrm{M})$ for the same preparations were averaged for this calculation. The results for the example in Figure $3 A-C$ is shown (Fig. $3 I$ ). $5-\mathrm{HT}_{1 \mathrm{~B} / 1 \mathrm{D}}$ receptor activation had no effect on total ventral root output power during the locomotor bout. Data were again normalized to the maximum response in control to calculate mean effect of kynurenate and L694-247 in all preparations (Fig. 3J) (mean ventral root power in $0.1 \mu \mathrm{M} \mathrm{L694-247} \mathrm{was} 96 \pm$ $10 \%$ of control; not significantly altered; $n=5$ preparations). We compared this quantification to the effect of kynurenate. In contrast to $5-\mathrm{HT}_{1 \mathrm{~B} / 1 \mathrm{D}}$ receptor activation, kynurenate $(200 \mu \mathrm{M})$ completely eliminated patterned ventral root activity. Accordingly, ventral root output power was almost abolished by $200 \mu \mathrm{M}$ kynurenate (Fig. 3C, I,J) (output reduced to just $10 \pm 4 \%$ of control; $p<0.01 ; n=5$ preparations). Thus, the effect of $5-\mathrm{HT}_{1 \mathrm{~B} / 1 \mathrm{D}}$ receptors on spinal locomotor output was quantitatively and qualitatively different from either a simple reduction of descending drive to the spinal cord (Sirota et al., 2000) as would be seen after a reduction in release probability at glutamatergic synapses.

In the isolated spinal cord during fictive locomotion activated by exogenously applied glutamatergic agonists, $5-\mathrm{HT}_{1 \mathrm{~B} / 1 \mathrm{D}}$ receptors modify motor activity by inhibiting output from EINs (Parker and Grillner, 1999; Schwartz et al., 2005). However, remaining fictive locomotion might result from properties of glutamate receptors activated directly by the exogenous agonists, rather than by synaptic glutamate release. Indeed, block of AMPA receptors does not prevent NMDA-evoked fictive locomotion (Alford and Grillner, 1990). Determining the effect of 5-HT receptor agonists applied to the spinal cord during brainstem-activated fictive locomotion averts this caveat. Thus, given that ventral root output power is unaffected, the effects of 5-HT and L694-247 are paradoxical if we consider presynaptic 5-HT G-protein-coupled receptors (GPCRs) to act simply as presynaptic inhibitors. If activation of presynaptic $5-\mathrm{HT}_{1 \mathrm{~B} / 1 \mathrm{D}}$ receptors profoundly inhibits descending excitation of spinal CPGs, how does fictive locomotor output power remain mostly unaltered? To answer this, we investigated the properties of presynaptic inhibition by 5 -HT receptors during physiological patterns of activity necessary to sustain fictive locomotion. 
Reticulospinal synaptic transmission and $\mathrm{Ca}^{2+}$ accumulation during repetitive stimulation

Previous studies characterizing reticulospinal synaptic transmission and the mechanism of 5-HT-mediated inhibition probed synaptic responses to single stimuli. In contrast, during MLR-induced locomotion, reticulospinal neurons fire bursts of action potentials (up to $50 \mathrm{~Hz}$ ) (Brocard and Dubuc, 2003) (Fig. 1) in phase with the ipsilateral and rostral spinal cord. These repetitive trains of action potentials may cause presynaptic residual $\mathrm{Ca}^{2+}$ accumulation. 5- $\mathrm{HT}_{1 \mathrm{~B} / 1 \mathrm{D}}$ receptors inhibit release via $\mathrm{G} \beta \gamma$ (Schwartz et al., 2005), which competes with synaptotagmin (the $\mathrm{Ca}^{2+}$ sensor for exocytosis) (Blackmer et al., 2001; Gerachshenko et al., 2005; Yoon et al., 2007) for binding to the SNARE complex. Thus, raised $\left[\mathrm{Ca}^{2+}\right]$ prevents 5-HT-mediated inhibition by allowing synaptotagmin to outcompete $\mathrm{G} \beta \gamma$ for SNARE complex binding (Yoon et al., 2007). We wanted to determine how this competition might modify physiologically relevant trains of evoked synaptic events. Therefore, we investigated stimulus train-evoked $\mathrm{Ca}^{2+}$ accumulation in presynaptic terminals of reticulospinal axons. Axons were recorded with microelectrodes and injected through this microelectrode with the low-affinity $\mathrm{Ca}^{2+}$ indicator Fluo-5F. Action potential trains were evoked in reticulospinal axons (10 shocks; $50 \mathrm{~Hz}$ ) and the $\mathrm{Ca}^{2+}$ transient recorded by confocal line-scanning microscopy with the $\mathrm{x}$-scan aligned along the axon plasma membrane (Takahashi et al., 2001) (Fig. 4A) to allow $500 \mathrm{~Hz}$ resolution of presynaptic $\mathrm{Ca}^{2+}$ entry.

The peak $\mathrm{Ca}^{2+}$ transient was estimated at $1.2 \mu \mathrm{M}$ at the first presynaptic action potential and $2.0 \mu \mathrm{M}$ at the last. Although this underestimates peak $\mathrm{Ca}^{2+}$ concentrations at the active zone (see Materials and Methods), these responses were well within the linear response of the dye $\left(K_{\mathrm{d}}=3.7 \mu \mathrm{M}\right.$ at $\left.10^{\circ} \mathrm{C}\right)$, and thus, the lack of effect of 5-HT is not attributable to dye saturation. The mean increase in $\mathrm{Ca}^{2+}$ transient amplitude between the first and last stimulus was $1.8 \pm 0.1$-fold $(n=6)$ and was unaffected by 5 -HT (Fig. $4 A b$ ) $(0.3-3 \mu \mathrm{M})$. This rise in presynaptic $\mathrm{Ca}^{2+}$ during the stimulus is sufficient to prevent 5-HT-mediated presynaptic inhibition based on our previously published results (Yoon et al., 2007). Indeed, experimentally induced presynaptic $\mathrm{Ca}^{2+}$ transients 1.4 -fold over control prevent 5-HT-mediated inhibition (Yoon et al., 2007).

To determine the effect of 5-HT on synaptic responses during stimulus trains, paired recordings were made between reticu-
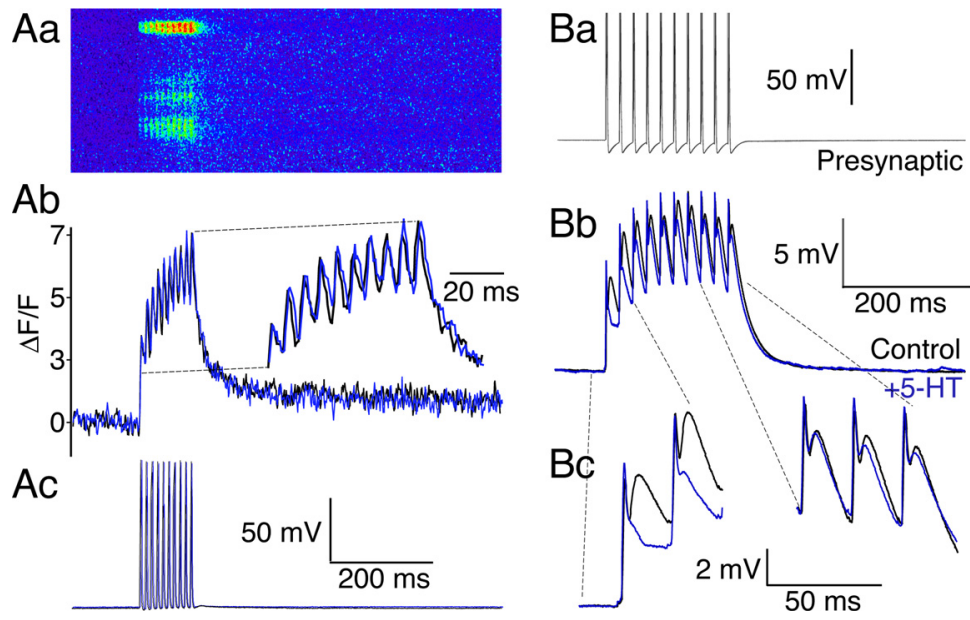

Figure 4. Presynaptic residual $\mathrm{Ca}^{2+}$ at presynaptic terminals coincides with a train-dependent loss of 5-HT-mediated presynaptic inhibition. $\boldsymbol{A}$, Presynaptic $\mathrm{Ca}^{2+}$ transients were recorded by confocal line-scanning along the axonal plasma membrane at $500 \mathrm{~Hz}$. Aa, Line-scan recording of $\mathrm{Ca}^{2+}$ dye fluorescence in axon (3 active zones). Axon labeled with low-affinity $\mathrm{Ca}^{2+}$ dye Fluo $5 \mathrm{~F}$ from a recording microelectrode. Ten action potentials, $50 \mathrm{~Hz}$, evoked summating $\mathrm{Ca}^{2+}$ transients. $\boldsymbol{A} \boldsymbol{b}, \mathrm{Ca}^{2+}$ transients displayed as $\Delta$ F/F from uppermost active zone (control, black; 5-HT, $1 \mu \mathrm{M}$, blue). The time base of the traces is expanded in the inset to clearly demonstrate the absence of any effect of 5-HT. Ac, Presynaptic action potential train that caused the $\mathrm{Ca}^{2+}$ transients (control, black; 5-HT, $1 \mu \mathrm{m}$, blue) evoked by stimulation through the recording electrode. $A a-A c$ are aligned and shown with the same time base. $\boldsymbol{B}$, Current-clamp recording of train stimulation. $\mathbf{B a}$, Ten presynaptic action potentials, $50 \mathrm{~Hz}$ evoked through the presynaptic recording electrode. $\boldsymbol{B} \boldsymbol{b}$, Average of 10 sequential postsynaptic traces in control (black) and in 5-HT (0.6 $\mu \mathrm{m}$; gray). Note the effect of $5-\mathrm{HT}$ is limited to the start of the train. $\mathbf{B C}$, Expanded recording of the first two and last three EPSPs in the train to emphasize the loss of inhibitory effect of $5-\mathrm{HT}$ at the end of the train. The initial absolute voltage of the last three traces was adjusted to that of control to emphasize the later responses in the train were not significantly inhibited by 5-HT.
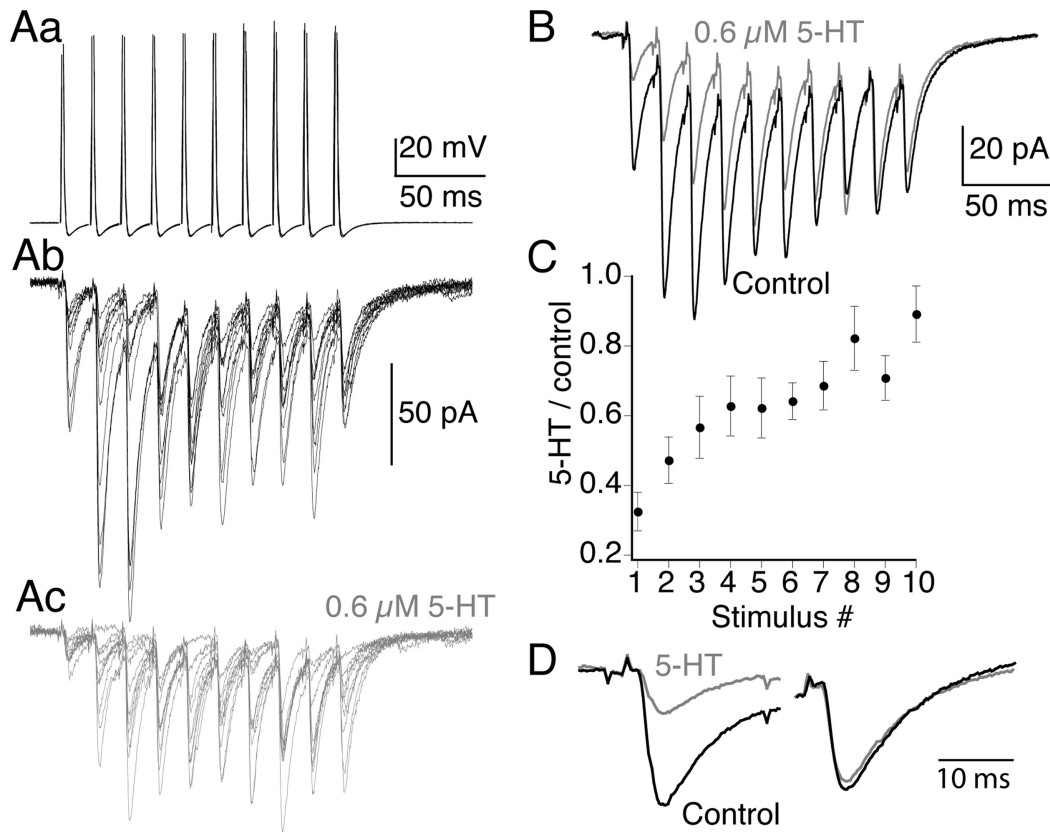

Figure 5. 5-HT-mediated inhibition of AMPA receptor-mediated EPSCs is lost during train stimulation of the presynaptic axon. $\boldsymbol{A}$, Paired recordings demonstrate train evoked AMPA receptor-mediated EPSCs (10 action potentials; $50 \mathrm{~Hz}$ in each train). $\boldsymbol{A a}$, Presynaptic action potentials. $\boldsymbol{A} \boldsymbol{b}$, Ten sequential evoked EPSC trains in control and in 5-HT (AC) (600 nm; gray). $\boldsymbol{B}$, Means of the 10 traces shown in $\boldsymbol{A} \boldsymbol{b}$ and $\boldsymbol{A c}$. Control, Black; 5-HT, gray. $\boldsymbol{C}$, Ratio of EPSC amplitudes in 5-HT to control for the means of each of the 10 sequential responses in the train ( $n=9$ preparations and pairs). 5 -HT markedly inhibited the EPSCs early in the train but the response recovered toward the end. Error bars indicate SEM. D. The first and last traces are expanded and overlaid to emphasize the loss of inhibition at the end of the train. 


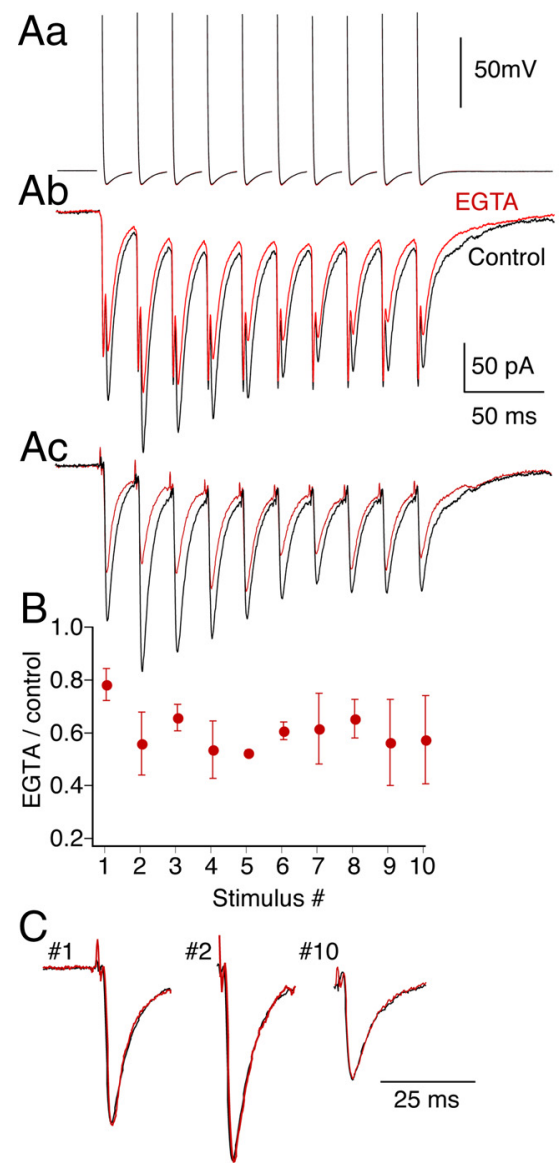

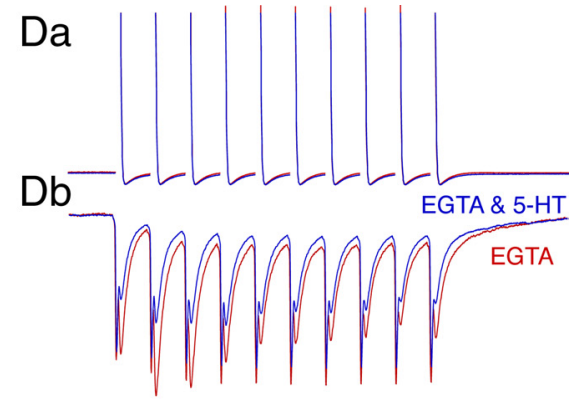

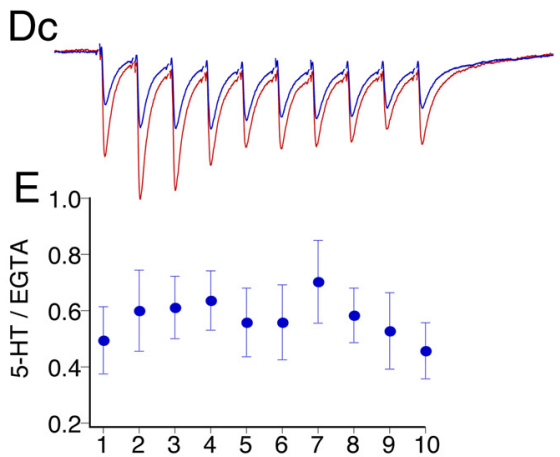

$\mathrm{F}$

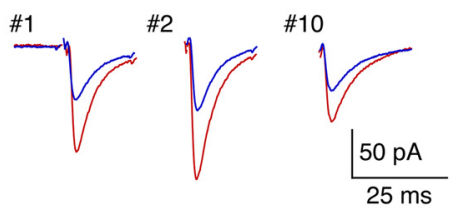

Figure 6. Train-dependent loss of 5-HT-mediated inhibition is prevented by presynaptic injection of EGTA.A, Paired recording between presynaptic reticulospinal axon and postsynaptic neuron in which EGTA (100 mM) was included in the presynaptic electrode. Aa, Presynaptic action potentials before (black) and after (red) pressure injection of EGTA into the axon. EGTA left action potentials unaffected throughout the train. $\boldsymbol{A} \boldsymbol{b}$, Postsynaptic EPSCs comprising electrical and chemical components evoked by presynaptic action potentials. Traces are averages of 10 responses before and after injection of EGTA into the presynaptic axon. $\boldsymbol{A c}$, Chemical EPSCs after subtraction of the electrical components that were obtained after blocking AMPA-mediated responses with CNQX. B, Effect of EGTA injection as proportional inhibition for each of the 10 EPSCs in the train. Data are from four paired recordings and normalized to control amplitudes of each EPSC. The first response was inhibited to a lesser extent than later responses in the train. C, As representative examples, the first, second, and last EPSCs in the train were compared before and after EGTA injection. The responses after EGTA were scaled to the peak amplitudes of the control responses. The kinetics of the responses (both rise and decay) were unaltered. $\boldsymbol{D}$, Paired recordings from cell in $\boldsymbol{A}$; red traces are the same as those in $\boldsymbol{A}$ after presynaptic EGTA injection. $\boldsymbol{D a}$, Presynaptic action potentials. Db, Evoked EPSCs in EGTA and 5-HT ( $600 \mathrm{~nm}$; blue). Dc, Traces after subtraction of electrical components. E, Ratio of EPSC amplitudes in 5-HT to control ( $n=5$ preparations and pairs). 5 -HT inhibited EPSCs throughout the train after presynaptic EGTA injection. Error bars indicate SEM. $\boldsymbol{F}$, The first, second, and last traces are expanded to emphasize that inhibition is sustained throughout the train.

EPSP in train reduced to $52 \pm 6 \%$ of control; $p<0.01$ ) (Fig. $4 B$ ), but the EPSPs recover to control at the termination of the train (Fig. $4 B)(n=3)$.

These current-clamp experiments indicate a physiologically relevant relaxation of 5-HT-mediated inhibition that parallels summation of $\mathrm{Ca}^{2+}$ during the stimulus train. To quantify traindependent effects of 5-HT on AMPA receptor EPSCs, paired recordings were made between reticulospinal axons and whole-cell voltage-clamped ventral horn neurons at $-70 \mathrm{mV}$ to reveal AMPA receptor-mediated EPSCs. The presynaptic axon was repetitively stimulated (10 stimuli; $50 \mathrm{~Hz}$ ) in a series of trains (Fig. $5 A$ shows 10 sequential responses to trains in control and in 5 -HT) to reveal the quantal variance in the postsynaptic response. 5-HT (0.3-1 $\mu \mathrm{M})$ markedly depressed AMPA receptormediated EPSCs at the start of the train; however, this inhibition was lost over the later stimuli. To reveal the extent of inhibition and its loss at the end of the train, responses to 20 trains in control and after application of 5-HT were averaged in each of the recorded pairs (Fig. 5B). The mean EPSC at the start of the train was consistently inhibited, and those at the end were not (Fig. 5C,D) (first EPSC inhibited to $33 \pm 6 \%$ of control in $0.6 \mu \mathrm{M} 5-\mathrm{HT}$; 10 th response in the train was $88 \pm 9 \%$ of control; $n=8$ ) similar to current-clamp recordings.

Enhanced presynaptic $\mathrm{Ca}^{2+}$ transients in high extracellular $\mathrm{Ca}^{2+}$ prevent $5-\mathrm{HT}_{1 \mathrm{~B} / 1 \mathrm{D}}$ receptor-mediated presynaptic inhibition (Yoon et al., 2007). We now show, similarly, that when presynaptic $\mathrm{Ca}^{2+}$ concentrations are raised during physiologically relevant stimulus trains (Fig. 4), 5-HTmediated presynaptic inhibition is lost. However, during repetitive stimulation, $\mathrm{Ca}^{2+}$ may represent only one of a number of effects mediating short-term plasticity. Thus, to determine whether $\mathrm{Ca}^{2+}$ summation at the active zone can account for the loss of 5-HT-mediated inhibition during the stimulus train, we prevented frequency-dependent residual $\mathrm{Ca}^{2+}$ accumulation. Reticulospinal axons were recorded from and microinjected with the slow binding $\mathrm{Ca}^{2+}$ buffer, EGTA, to mitigate train evoked presynaptic $\mathrm{Ca}^{2+}$ summation. EGTA does not prevent individual evoked EPSCs because it does not bind $\mathrm{Ca}^{2+}$ sufficiently rapidly to prevent its immediate binding to synaptotagmin (Adler et al., 1991). However, EGTA will reduce the slower accumulation of residual $\mathrm{Ca}^{2+}$ at the active zone during repetitive stimulation. We injected EGTA into the presynaptic axons (electrode contained $100 \mathrm{~mm}$ EGTA, 5 mm HEPES, $1 \mathrm{~m} \mathrm{KCl}$, $\mathrm{pH} 7.2 ; n=5)$. All chemical EPSCs in the train are inhibited by this injection (Fig. 6A); however, the first response is significantly less inhibited than the immediately subsequent responses (mean reduction of first response to $78 \pm 6 \%$ of control; mean of all later responses was to $58 \pm 2 \%$ of control; $p<0.05$ ) (Fig. $6 B$ ). Note that the immediate shortterm enhancement of the postsynaptic response over the beginning of the train coincides with a rise in presynaptic residual $\mathrm{Ca}^{2+}$ (Fig. 4). The later depression of the response is common at this synapse, although the underlying mechanism remains unclear. Importantly, for these experiments, the presynaptic injection did not block EPSCs, nor did it alter the kinetic profile of the individual responses during the stimulus train (Fig. 6C, traces after EGTA scaled to control peak amplitude for clarity).

After presynaptic EGTA injection, 5-HT ( $0.6 \mu \mathrm{M})$ inhibited EPSCs uniformly throughout the presynaptic action potential train (Fig. 6D) (first response reduced to $49 \pm 12 \%$ of control; not significantly different from results without EGTA; last response reduced to $43 \pm 10 \%$ of control; not significantly 

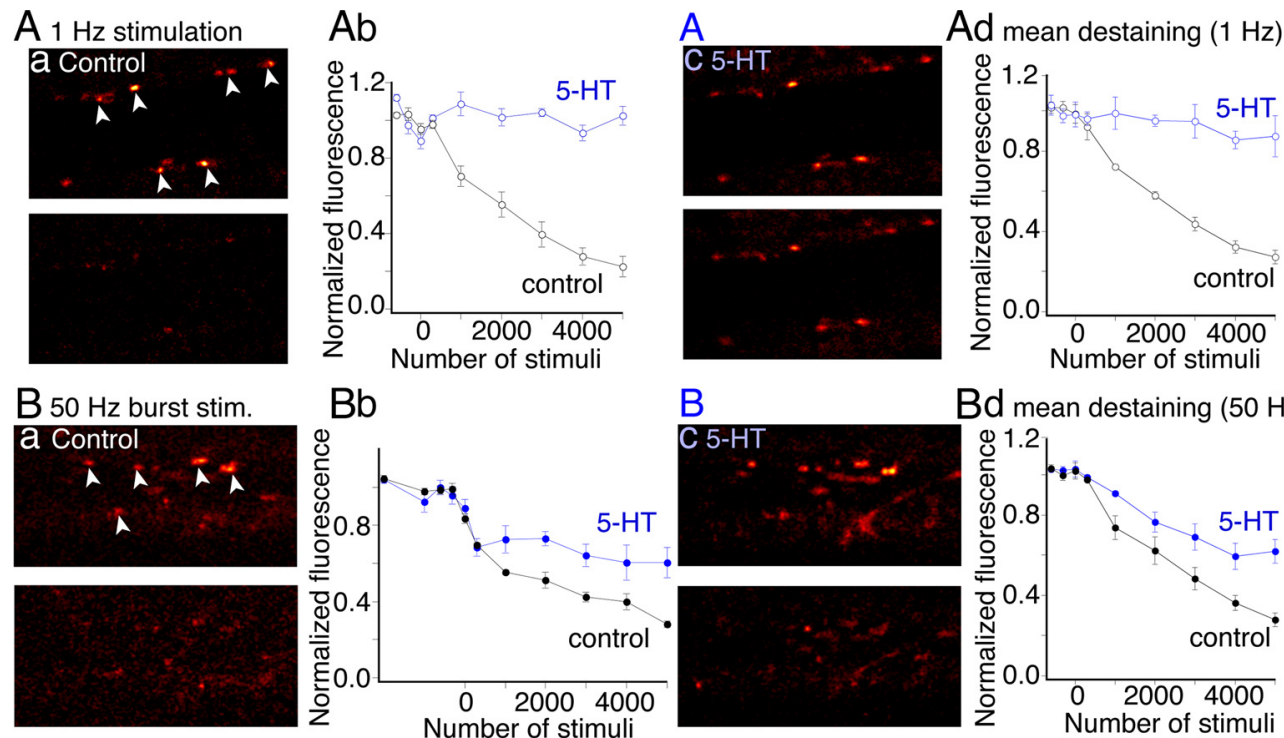

Bd mean destaining $(50 \mathrm{~Hz})$
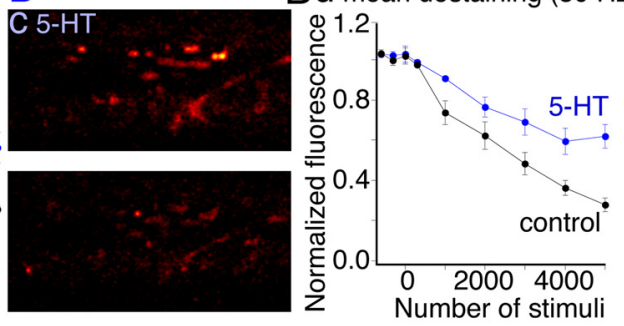

Figure 7. Effect of train stimulation on FM1-43 destaining of synaptic vesicle clusters. Aa, FM1-43-labeled presynaptic terminals, before (top) and after (bottom) destaining at $1 \mathrm{~Hz}$ in control. $\boldsymbol{A} \boldsymbol{b}$, The black trace shows control destaining versus stimulus number of the terminals arrowed. The same presynaptic axon and terminals were restained with FM1-43 (Ac), and then superfused with 5-HT ( $600 \mathrm{nm)}$. Stimulation (1 Hz) subsequently failed to destain ( $\boldsymbol{A} \boldsymbol{b}$; blue). $\boldsymbol{A} \boldsymbol{d}$, Mean of data plotted as for $\boldsymbol{A} \boldsymbol{b}$ from all five preparations. $\boldsymbol{B} \boldsymbol{a}$, Presynaptic terminals (examples arrowed) labeled as in $\boldsymbol{A}$ but destained with action potentials in trains ( $10 \mathrm{at} 50 \mathrm{~Hz} ; 10$ s intervals) with the same total number of stimuli as in $\boldsymbol{A}$. In control, destaining was indistinguishable from $1 \mathrm{~Hz}$ destaining ( $\boldsymbol{B} \boldsymbol{b}$, black). Axons and presynaptic terminals were restained (BC) and reimaged. In 5-HT ( $600 \mathrm{nM})$, partial destaining was observed (blue). $\boldsymbol{B} \boldsymbol{d}$, Mean of data plotted from all four preparations. Error bars indicate SEM.

different from effect of 5-HT on first response) (Fig. 6E,F). Thus, the inhibitory effect of 5-HT on late responses during trains of presynaptic action potentials was significantly enhanced after presynaptic EGTA injection $(p<0.05)$. We conclude that summation of presynaptic residual $\mathrm{Ca}^{2+}$ during stimulus trains mediates loss of 5-HT-mediated inhibition. This effect is consistent with a $\mathrm{Ca}^{2+}$-synaptotagmin competition with $\mathrm{G} \beta \gamma$ at the SNARE complex.

\section{High stimulus frequency enhances FM1-43 destaining} in 5-HT

The results above reveal that, during physiological stimulation paradigms, 5-HT acts as an activity-dependent modulator of neurotransmission, not simply an inhibitor. In addition, competition between G $\beta \gamma$ and synaptotagmin at the SNARE complex (Yoon et al., 2007) means that $\mathrm{Ca}^{2+}$ accumulation during stimulus trains (Figs. 4, 5) will reduce 5-HT effects under high-frequency activity seen during the activation of locomotion (Figs. 1-3).

5-HT has been shown to modify vesicle fusion. A dose of 5-HT $(0.6 \mu \mathrm{M})$ that partially inhibits EPSCs completely blocks FM1-43 destaining from the vesicles during stimulation at 1 $\mathrm{Hz}$ (Photowala et al., 2006) - a condition in which residual $\mathrm{Ca}^{2+}$ does not accumulate. We, therefore, wanted to determine whether the stimulus train-dependent recovery of 5-HTinhibited AMPA receptor-mediated EPSCs is mirrored by a similar train-dependent recovery of FM1-43 destaining in 5 -HT. Synaptic vesicles in single giant axons were labeled with FM1-43. Axons were stimulated (1000 stimuli; $1 \mathrm{~Hz}$ ) through an intracellular microelectrode in the presence of FM1-43 (5 $\mu \mathrm{M})$. After stimulation, FM1-43 perfusion was stopped and excess dye was removed with Advasep-7 (1 mM) (Kay et al., 1999). Vesicles were then destained by additional stimulation at $1 \mathrm{~Hz}$ (Fig. 7A). After 5000 stimuli, the mean presynaptic vesicle cluster fluorescence intensity was reduced to $27 \pm 3 \%$ of the prestimulus fluorescence ( $n=15$ active zones, 3 preparations; $p<0.01$ ) [Fig. 7Ad for data in all preparations, similar to previous results (Photowala et al., 2006)]. The same axons were restained (Fig. 7Ac), and then 5-HT was added to the superfusate. As previously reported, 5-HT $(0.6 \mu \mathrm{M})$ abolished destaining during $1 \mathrm{~Hz}$ stimulation (Photowala et al., 2006) (Fig. $7 A b, c$ ) (fluorescence after 5000 stimuli was now $87 \pm 10 \%$ of prestimulus fluorescence).

During bursts of 10 stimuli at $50 \mathrm{~Hz}, 5-\mathrm{HT}$-mediated presynaptic inhibition recorded electrophysiologically was lost toward the end of the stimulus train as $\mathrm{Ca}^{2+}$ accumulated presynaptically (Figs. 4-6). We, therefore, determined whether 5-HTmediated trapping of FM1-43 in synaptic vesicle clusters was also prevented by high-frequency stimulation. Thus, in an additional four preparations, axons were similarly stained with FM1-43 but destained with a series of action potential trains $(10$ at $50 \mathrm{~Hz})$. Presentation of trains at $10 \mathrm{~s}$ intervals ensured that the total number of stimuli over time was identical with $1 \mathrm{~Hz}$ stimulation (Fig. 7A). Control destaining was similar to destaining during continuous $1 \mathrm{~Hz}$ stimulation (Fig. $7 B a, b$ ) (staining reduced to $28 \pm 3 \%$ of prestimulus fluorescence; 20 active zones in four preparations; black trace). The terminals were restained, 5-HT $(0.6 \mu \mathrm{M})$ applied, and the axon again stimulated with a series of trains. FM1-43 destaining with $50 \mathrm{~Hz}$ trains in 5-HT was significantly greater than after continuous stimulation at $1 \mathrm{~Hz}$ in 5 - $\mathrm{HT}$, although less than control destaining (after 5000 stimuli, staining was reduced to $62 \pm$ $6 \%$ of prestimulus fluorescence) (Fig. $7 B d, p<0.05$; blue trace). This intermediate destaining rate at $50 \mathrm{~Hz}$ in $5-\mathrm{HT}$ suggests that trains of stimuli enhance destaining of FM1-43 in 5-HT. A loss of FM1-43 trapping also implies that the kissand-run fusion mode caused by 5-HT (Photowala et al., 2006) appears to be lost during the stimulus train. Moreover, this effect is consistent with the frequency-dependent recovery of synaptic transmission inhibited by $5-\mathrm{HT}$. 


\section{High stimulus frequency reverses 5-HT-dependent} reductions in cleft glutamate concentration

Consistent with its effect on vesicle fusion, 5-HT causes reductions in evoked cleft glutamate concentration after single synaptic stimuli (Schwartz et al., 2007). If train stimulation enhances FM1-43 destaining from fusing vesicles in 5-HT (Photowala et al., 2006) by causing full synaptic vesicle fusion at the end of the train even in 5-HT, then we may hypothesize that in 5-HT cleft glutamate concentrations rise as presynaptic residual $\mathrm{Ca}^{2+}$ summates during the stimulus train (Photowala et al., 2006; Schwartz et al., 2007). This can be determined by measuring efficacy of block of glutamate receptor-mediated EPSCs by low-affinity antagonists (Clements et al., 1992) in which a portion of the EPSC is attributable to nonequilibrium antagonist unbinding and its competitive replacement by synaptic glutamate. The degree to which the antagonist is replaced depends on glutamate concentration. For EPSCs evoked by a single stimulus, both low-affinity AMPA and NMDA receptor antagonists revealed a supralinear inhibition of synaptic events in 5-HT, indicating a reduction in synaptic cleft glutamate (Schwartz et al., 2007).

Using paired cell recordings, we probed glutamate cleft concentrations with kynurenate during presynaptic action potential trains $(10$ at $50 \mathrm{~Hz}$ ) (Fig. $8 \mathrm{Aa}$ ). The effect of kynurenate at a half-maximal dose $(200 \mu \mathrm{M})$ (Fig. $8 A b$, gray) was uniform on each sequential EPSC ( $n=5$; kynurenate reduced the first response to $51 \pm 6 \%$ of control, and the last to $55 \pm 5 \%$ of control) (Fig. $8 B$, gray). Thus, in control, peak glutamate concentrations are unaffected by repetitive stimulation at $50 \mathrm{~Hz}$. This is consistent with our previous finding that changes in release probability do not alter synaptic cleft glutamate concentrations (Schwartz et al., 2007). 5-HT (Fig. 8 Ac, gray) preferentially inhibited the early EPSCs in the train. We then probed this response in 5-HT with kynurenate $(200 \mu \mathrm{M})$. Early responses in the train in 5-HT were inhibited by kynurenate to a much greater extent (to $27 \pm 3 \%$ of the first response in 5-HT) (Fig. $8 \mathrm{~B}$, closed circles) than the control effect of kynurenate alone (open circles). This result confirms that 5-HT lowers synaptic glutamate concentrations for the first stimulus in the train (Schwartz et al., 2007). However, as the train progressed, the kynurenate block became indistinguishable from its effect against control responses as if no 5-HT were present (Fig. 8Ac,B) (EPSC amplitude reduced to $53 \pm 7 \%$ of last response in 5-HT alone; not significantly different from effect of kynurenate with no 5-HT present). We conclude that, during stimulus trains in 5-HT, cleft glutamate concentrations recover to control levels as 5-HT-mediated inhibition is overcome by rising presynaptic $\left[\mathrm{Ca}^{2+}\right]$ and synaptic vesicle fusion is more complete. Thus, 5-HT-mediated presynaptic inhibition is relaxed during repetitive stimulation characteristic of reticulospinal neuron activity that evokes locomotion.

\section{Differential efficacy of 5-HT on AMPA and NMDA receptor-mediated responses}

5-HT lowers evoked synaptic cleft glutamate concentrations (Schwartz et al., 2007), which favors synaptic activation of NMDA over AMPA receptors (Choi et al., 2003). In lamprey, presynaptic 5-HT receptors inhibit AMPA receptor-mediated EPSCs more effectively than NMDA EPSCs at the same synapses (Schwartz et al., 2007). To test whether synaptic NMDA receptor activation is similarly resistant to inhibition by 5 -HT during stimulus trains, we made paired recordings between reticulospinal axons - the output compartment of the MRRN neurons recorded in Figure 1-and their postsynaptic ventral horn target neurons that comprise the locomotor CPG (see supplemental

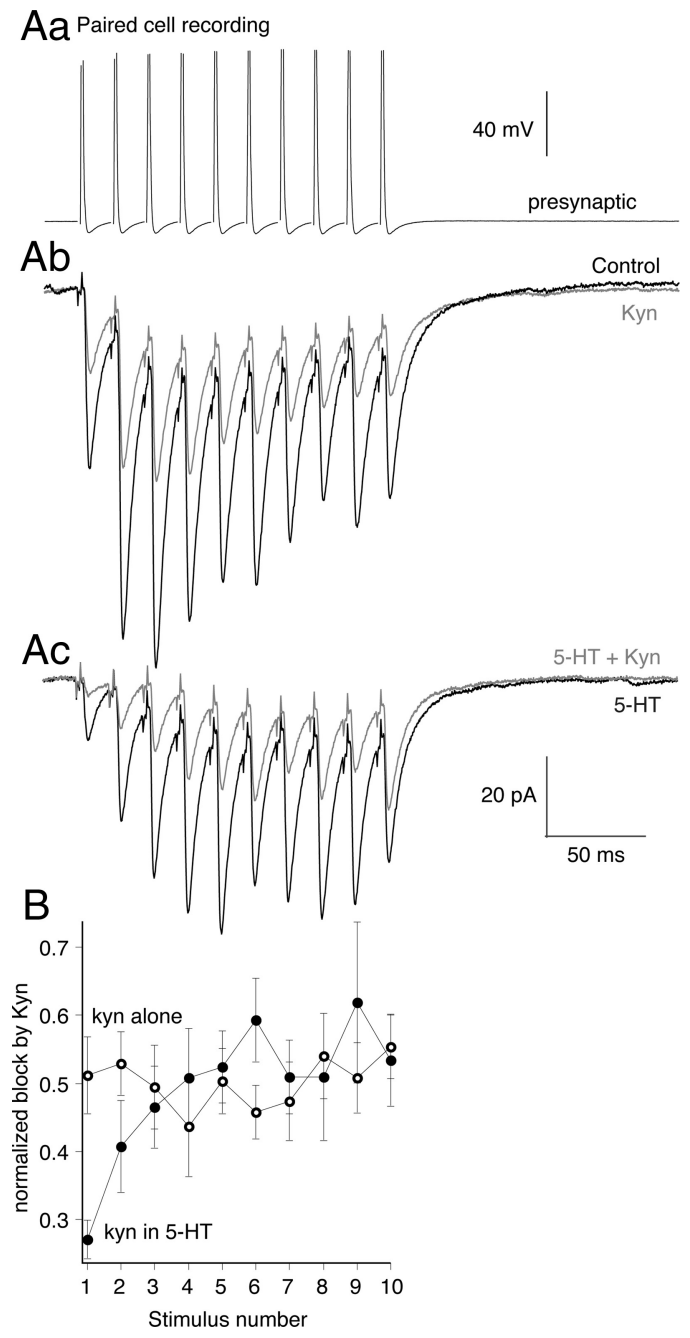

Figure 8. 5-HT lowers evoked cleft glutamate concentrations at the start of train stimuli but not at the end. $A$, To probe glutamate concentration, paired recordings were made. Presynaptic action potentials $(\boldsymbol{A a})(10 \mathrm{at} 50 \mathrm{~Hz})$ evoked EPSCS $(\boldsymbol{A} \boldsymbol{b})$ in control (black). Kynurenate (200 $\mu \mathrm{m}$; gray) reduced EPSC amplitudes throughout the train. Ac, 5-HT (600 nM) reduced EPSC amplitudes at the start of the train but not the end (compare black trace in $\boldsymbol{A} \boldsymbol{b}$ to black trace in $\boldsymbol{A} \boldsymbol{c}$ ). In 5 - $\mathrm{HT}$, kynurenate (200 $\mu \mathrm{m}$; gray) was more effective at inhibiting EPSCs at the start of the train than the end. $\boldsymbol{B}$, Graphs comparing the efficacy of kynurenate at blocking EPSCs throughout the stimulus train. In 5-HT (filled circles; $n=9$ ), kynurenate was more effective at inhibiting the early EPSCs in 5-HT compared with control (open circles; $n=3$ ). Error bars indicate SEM.

Fig. 1, available at www.jneurosci.org as supplemental material). We voltage clamped the postsynaptic cell and stimulated the reticulospinal axon with a burst of action potentials ( 10 shocks; $50 \mathrm{~Hz}$ ) (Fig. 9B) in $\mathrm{Mg}^{2+}$-free superfusate to enhance NMDA receptormediated EPSCs at $-70 \mathrm{mV}$. CNQX or NBQX (2,3-dioxo-6-nitro1,2,3,4-tetrahydrobenzo[f] quinoxaline-7-sulfonamide) (5 $\mu \mathrm{M})$ was added to reveal the slow summating NMDA receptor response under the electrical component (Fig. 9B). 5-HT (0.6 $\mu \mathrm{M})$ had no effect on the NMDA component throughout these bursts (Fig. $9 B, C)(n=4)$. We conclude that 5-HT at doses that substantially inhibit AMPA receptor-mediated EPSCs and modify locomotor activity (Fig. 9A), failed to inhibit NMDA EPSCs whether evoked by single stimuli (Schwartz et al., 2007) or during physiologically relevant activity trains.

Thus, during repetitive stimulation, as during single synaptic responses, 5-HT receptor activation favors postsynaptic activation of NMDA receptors over AMPA. Spinal application of 


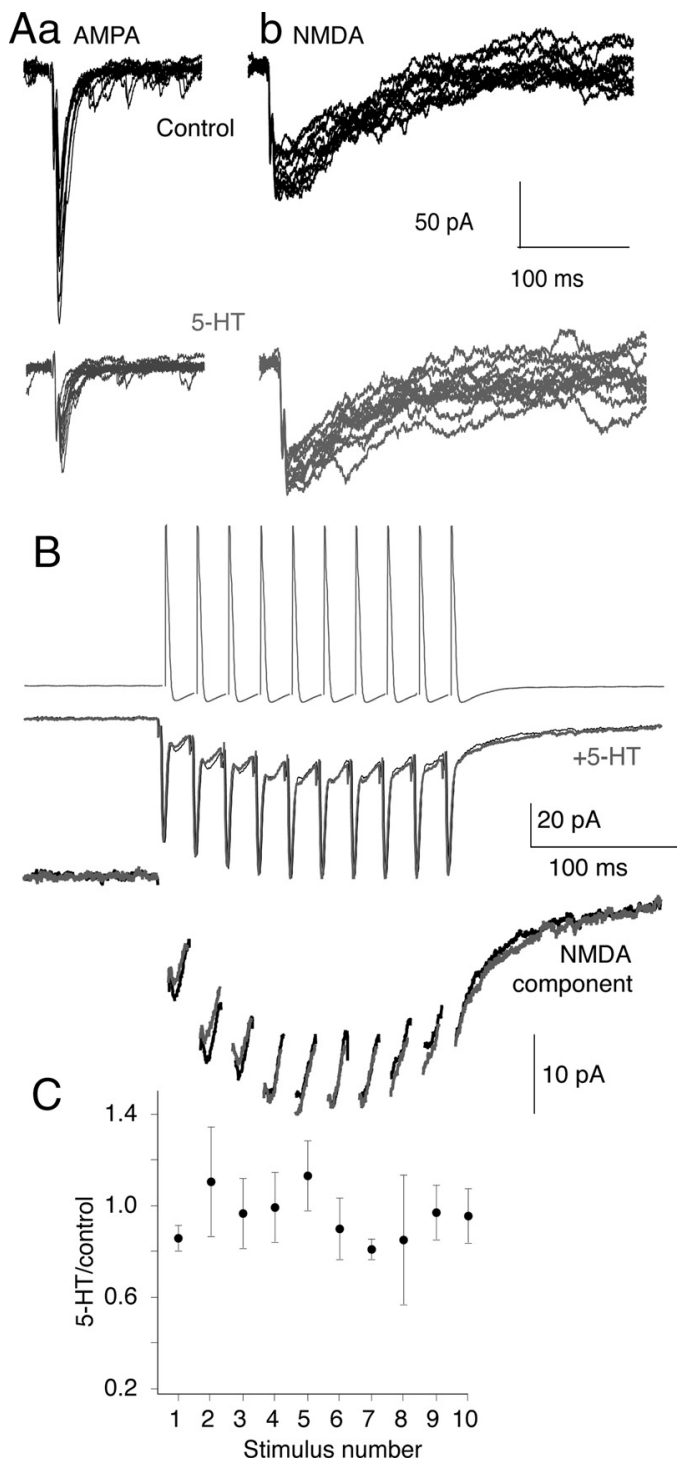

Figure 9. 5-HT differentially modifies the amplitude of NMDA- and AMPA-mediated synaptic responses. $A$, Whole-cell postsynaptic voltage-clamp recording of control EPSCS, evoked by 12 sequential stimulations of a paired presynaptic reticulospinal axon. $\boldsymbol{A} \boldsymbol{a}$, Responses in control to show AMPA receptor-mediated EPSCs (black, top). Bottom trace (gray), After application of 5-HT $(0.6 \mu \mathrm{M}) . \boldsymbol{A} \boldsymbol{b}$, Responses recorded in $\mathrm{Mg}^{2+}$-free Ringer's and CNQX (5 $\left.\mu \mathrm{M}\right)$ to reveal the NMDA component. Bottom traces (gray), After addition of 5 -HT ( $0.6 \mu \mathrm{m}$ ). 5-HT had no effect on the NMDA EPSC. $\boldsymbol{B}$, Paired NMDA receptor EPSCs recorded in $\mathrm{Mg}^{2+}$-free Ringer's and CNQX (5 $\mu \mathrm{M}$ ) evoked by trains of sequential presynaptic action potentials ( $50 \mathrm{~Hz}$; 10 stimuli) in control (black) and in 5-HT (600 nm) (gray). The EPSCs are shown with an expanded $y$-axis in the bottom traces after removal of the electrical component for clarity. $\boldsymbol{C}$, Mean amplitudes of the evoked synaptic responses in the train. Each point is the mean ( \pm SEM) of each sequential EPSC recorded as the peak amplitude after the electrical component ( $n=3$ preparations). 5 -HT had no effect on the amplitude of the NMDA receptor-mediated EPSCs throughout the stimulus train.

NMDA activates locomotion (Brodin et al., 1985) and evokes bistable properties of spinal neurons (Sigvardt et al., 1985) that initiate slower locomotion than that evoked by AMPA receptors (Brodin et al., 1985; Tråvén et al., 1993). Therefore, we determined whether NMDA receptor block could prevent MLRactivated locomotion before and during spinal activation of $5-\mathrm{HT}_{1 \mathrm{~B} / 1 \mathrm{D}}$ receptors. Locomotor activity was initiated as above (Fig. 10). After obtaining reliable bouts of locomotion, the NMDA receptor antagonist D-AP5 $(50 \mu \mathrm{M})$ was applied to the spinal compartment. This prevented locomotion (Fig. 10A) $(n=$ 4 of 4 preparations). Locomotor activity was recovered on D-AP5 wash. Presynaptic 5-HT $1 \mathrm{~B} / 1 \mathrm{D}$ receptor activation with L694-247 $(0.1 \mu \mathrm{M})$ in the spinal compartment slowed locomotor activity (Fig. $10 \mathrm{~B})$, and D-AP5 $(50 \mu \mathrm{M})$ again prevented MLR-evoked locomotion.

NMDA receptor activity is, therefore, necessary for brainstemactivated locomotion but is not as strongly inhibited by presynaptic 5-HT receptors as AMPA receptor-mediated responses because the dose-response of 5-HT against NMDA EPSCs is right-shifted compared with AMPA EPSCs (Schwartz et al., 2007). Both in vitro and computer-modeling studies indicate that selective sparing of NMDA receptor-mediated responses favors low-frequency fictive locomotion (Brodin et al., 1985; Tråvén et al., 1993). Because presynaptic 5-HT receptor-meditated inhibition spares the NMDA receptormediated synaptic response, the relative contribution of NMDA receptors to excitation will be greater in 5-HT than in control locomotion.

\section{Discussion}

Neurotransmission is ubiquitously controlled by presynaptic GPCRs that use $\mathrm{G} \beta \gamma$ to inhibit release by membranedelimited mechanisms. G $\beta \gamma$ may modify presynaptic $\mathrm{Ca}^{2+}$ channels (Tedford and Zamponi, 2006) to reduce release probability. This causes a reduction of probability of any active zone releasing transmitter but no qualitative modulation in transmitter released at those active zones. In contrast, we previously demonstrated that GPCRs use G $\beta \gamma$ to directly target the release apparatus to alter fusion mode independently of release probability (Photowala et al., 2006). Thus, in 5-HT, vesicle fusion is dominated by kiss-and-run, trapping FM1-43 in fusing vesicles and reducing unitary quantal amplitudes (Photowala et al., 2006). This reduces cleft glutamate concentrations that can still activate NMDA receptors efficiently, but not AMPA receptors (Schwartz et al., 2007). We demonstrate that $5-\mathrm{HT}_{1 \mathrm{~B} / 1 \mathrm{D}}$ receptormediated reductions in synaptic cleft glutamate are modulated during stimulus trains that mimic brainstem-initiated motor behavior possibly linking frequency-dependent changes in fusion mode (Harata et al., 2006; Zhang et al., 2009) to $\mathrm{Ca}^{2+}$-dependent competition of synaptotagmin at the SNARE complex with G $\beta \gamma$ (Yoon et al., 2007).

5-HT profoundly modifies vertebrate locomotion. 5- $\mathrm{HT}_{1 \mathrm{~B} / 1 \mathrm{D}}$ receptors-presynaptic and inhibitory in vertebrates-reduce locomotion frequency (Schwartz et al., 2005). 5-HT is released diffusely from paracrine terminals (Van Dongen et al., 1985; Schotland et al., 1995) to act presynaptically and postsynaptically (Harris-Warrick and Cohen, 1985; Buchanan and Grillner, 1991; Parker and Grillner, 1999). However, selective activation of presynaptic $5-\mathrm{HT}_{1 \mathrm{~B} / 1 \mathrm{D}}$ receptors (Schwartz et al., 2005) mimics system-wide effects of 5-HT. Paradoxically, this receptor markedly inhibits output from the very neurons that convey descending brainstem commands to initiate and maintain locomotion. Yet, even at a dose $(1 \mu \mathrm{M})$ that inhibits single EPSCs by $83 \%$, brainstem-evoked locomotion is sustained. Indeed, the resultant slower locomotion is not simply a reduction in descending drive that would be seen after a reduction in $P_{r}$, because the sum of locomotor drive in each MLR induced bout of locomotion is unaffected by $5-\mathrm{HT}_{1 \mathrm{~B} / 1 \mathrm{D}}$ receptors. This lack of effect of 5-HT on integrated ventral root output, which is quantitatively similar to EMG activity in lamprey (Wallén and Williams, 1984), contrasts with manipulations used to alter total brainstem command output, in which total locomotor output power scales linearly with MLR stimulation used to evoke locomotion (Sirota et al., 2000).

To highlight this contrast between a generalized reduction in excitation and the effect of 5-HT, we demonstrate that even par- 

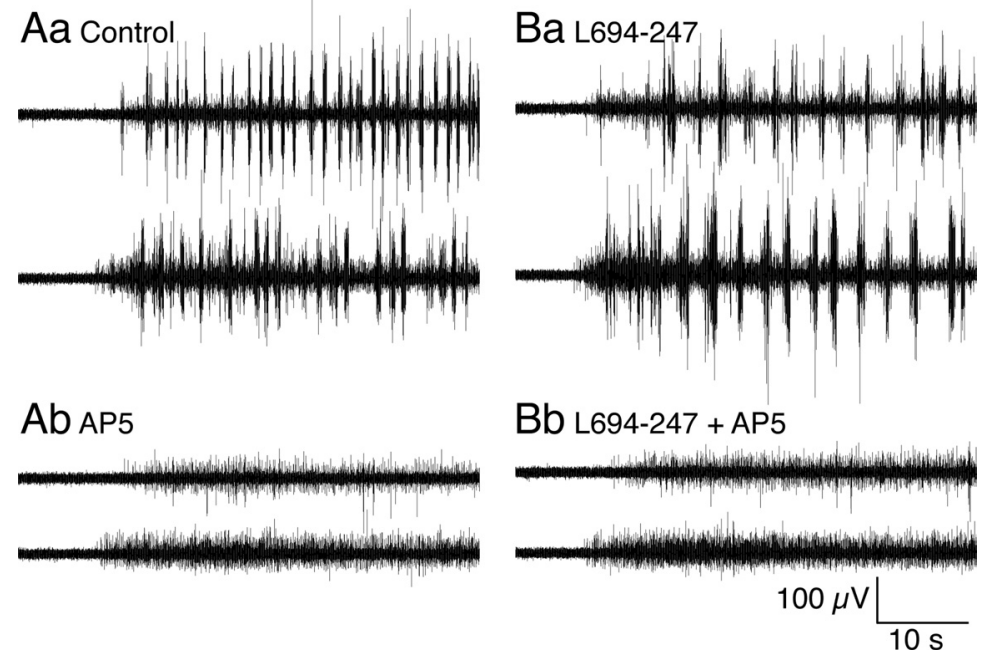

Figure 10. NMDA receptor activation is necessary for brainstem-evoked fictive locomotion. Aa, Left and right ventral root recordings after microinjection of L-glutamate (1 mM) into the MLR. Ab, Application of the NMDA receptor antagonist D-AP5 (50 $\mu \mathrm{M})$ to the pharmacologically isolated spinal cord abolished MLR evoked fictive locomotion. $B \boldsymbol{a}$, As for Figure 2, application of the $5 \mathrm{HT}_{1 \mathrm{~B} / 1 \mathrm{D}}$ receptor agonist L694-247 (0.1 $\left.\mu \mathrm{M}\right)$ slowed the ventral root bursting frequency. $\boldsymbol{B} \boldsymbol{b}, \mathrm{D}-\mathrm{AP5}(50 \mu \mathrm{M})$ applied in addition to L694-247 abolished fictive locomotion.

tial antagonism of spinal EPSCs completely blocks brainstemevoked locomotion. Thus, we conclude that 5-HT acts in a more complex manner. It is possible that presynaptic 5-HT receptors actively select for particular outputs to recruit alternate neuron pools that might underlie different motor synergies, a phenomenon recently reported for interneurons (McLean et al., 2008). However, this is unlikely because 5-HT inhibits every reticulospinal axon and EIN synapse that we investigated with various techniques (Blackmer et al., 2001; Takahashi et al., 2001; Gerachshenko et al., 2005; Schwartz et al., 2005, 2007; Photowala et al., 2006).

Reticulospinal neurons (Buchanan et al., 1987) and intraspinal EINs (Buchanan and Grillner, 1987) contribute to locomotor activity. Both are glutamatergic and output from both is inhibited by 5 -HT (Schwartz et al., 2005), with a similar profile of inhibition. During stimulus trains, early responses are inhibited, whereas recovery occurs late in the train (Parker and Grillner, 1999). Also in both synapses, 5-HT spares NMDA receptormediated responses compared with those mediated by AMPA receptors (Schwartz et al., 2005, 2007). Although the balance of excitation provided by the two groups of neurons is unknown, both contribute significantly to locomotion. Moreover, it is clear that reticulospinal neuron activity is absolutely required (Dubuc et al., 2008). Taking these characteristics into account, it becomes apparent that the complex features of 5-HT-mediated presynaptic inhibition are necessary to explain the effects of 5- $\mathrm{HT}_{1 \mathrm{~B}}$ receptors on locomotion. Experimentally determined results (Brodin and Grillner, 1986), and results obtained with computer modeling (Tråvén et al., 1993), indicate that selective spinal NMDA receptor activation favors lower locomotor frequencies and longer burst durations. Furthermore, computer models of the CPG indicate that excitatory responses that start depressed but then augment during bursts, like reticulospinal and EIN responses in 5-HT, favor lower frequency output (Kozlov et al., 2001). It is also striking that this effect is synergistic with the postsynaptic effects of 5-HT, which slow locomotion by acting at entirely different loci (Hounsgaard and Kiehn, 1989; Wallén et al., 1989; Zhong et al., 2006; Hammar et al., 2007). Clearly, whereas the presynaptic action of 5-HT is in one sense simple-
$\mathrm{G} \beta \gamma$ released in the presynaptic terminal directly targets the SNARE complex-it leads to complex synaptic and systemic outcomes.

We propose that the effect of $5-\mathrm{HT}_{1 \mathrm{~B} / 1 \mathrm{D}}$ receptor activation on locomotion results directly from the presynaptic cellular mechanism of action of this receptor. Presynaptic $5 \mathrm{HT}_{1 \mathrm{~B} / 1 \mathrm{D}}$ receptors use $\mathrm{G} \beta \gamma$, which competes with $\mathrm{Ca}^{2+}$-dependent synaptotagmin binding to SNARE complexes (Gerachshenko et al., 2005; Yoon et al., 2007). This evokes kiss-and-run vesicle fusion, reduces quantal amplitudes, and lowers synaptic cleft glutamate concentrations (Photowala et al., 2006; Schwartz et al., 2007). This outcome allows a selective inhibition of postsynaptic AMPA receptor-mediated EPSCs but, comparatively, spares postsynaptic NMDA receptor activation (Schwartz et al., 2007). The target for G $\beta \gamma$ liberated by the 5-HT receptor at primed vesicles provides an additional layer of complexity to $5-\mathrm{HT}_{1 \mathrm{~B} / 1 \mathrm{D}}$ receptor-mediated inhibition. $\mathrm{G} \beta \gamma$ competes with $\mathrm{Ca}^{2+}$ synaptotagmin binding to the SNARE complex, such that at raised presynaptic $\mathrm{Ca}^{2+}$ concentrations, $\mathrm{Ca}^{2+}$-synaptotagmin binding is more efficient and $G \beta \gamma$-mediated inhibition is lost (Yoon et al., 2007). In this study, we found that this $\mathrm{Ca}^{2+}$-dependent loss of presynaptic inhibition confers a frequency dependence on 5-HTmediated inhibition of glutamate release during physiologically relevant trains of activity. Thus, AMPA receptor-mediated EPSCs are inhibited at the start of stimulus trains but recover as $\mathrm{Ca}^{2+}$ concentrations summate in the presynaptic terminal during train stimulation to concentrations that we demonstrated prevent $\mathrm{G} \beta \gamma$-mediated presynaptic inhibition by allowing $\mathrm{Ca}^{2+}$-synaptotagmin to compete with G $\beta \gamma$ for binding to the SNARE complex (Yoon et al., 2007). Indeed, slow chelation of presynaptic $\mathrm{Ca}^{2+}$ abolished this frequency dependence of inhibition of AMPA receptor-mediated EPSCs.

Thus, we now demonstrate during stimulus trains that, at the start of the stimulus, a lower glutamate concentration released into the synaptic cleft after presynaptic 5-HT receptor activation can support activation of postsynaptic NMDA receptors even when substantial inhibition of AMPA receptors occurs (Schwartz et al., 2007). Moreover, as the stimulus train progresses, NMDA receptor responses are retained while AMPA receptor-mediated responses recover. We have now demonstrated that this mechanism, by which vesicle fusion mode is dynamically modulated during physiological relevant trains, qualitatively alters quantal neurotransmitter release and also accounts for the behavioral outcome of 5-HT in the spinal motor system.

We have provided a possible explanation as to how a presynaptic $5-\mathrm{HT}_{1 \mathrm{~B} / 1 \mathrm{D}}$ receptor located on locomotor command neurons can inhibit release without preventing locomotion. However, 5- $\mathrm{HT}_{1 \mathrm{~B} / 1 \mathrm{D}}$ receptors, which are located predominantly presynaptically, are linked to depression, aggression, memory impairment, attention deficit disorder, and defects in motor and sensory processes. Thus, can this mechanism have wider implications? Kiss-and-run fusion, as a mechanism involved in vesicle recycling, is well accepted during large dense core vesicle fusion events (Elhamdani et al., 2006). However, its presence and role at synapses has been more contentious. Under resting conditions, some authors have claimed extensive occurrence of this form of 
fusion (Zhang et al., 2009), others that it is rare but present (He et al., 2006), whereas others see no evidence (Balaji and Ryan, 2007). Regardless of the resting proportion of full to kiss-and-run fusion events, it has become clear that high-frequency stimulus trains may modify synaptic vesicle fusion in hippocampal neurons, from a state in which kiss-and-run occurs, to one favoring complete fusion (Harata et al., 2006), or an extended period of kiss-and-run vesicle fusion pore opening (Zhang et al., 2007, 2009).

It has been proposed that kiss-and-run fusion partially accounts for synapses in which NMDA receptor activation occurs, but AMPA responses are silenced (Choi et al., 2003). Modeling of AMPA receptor activation during kiss-and-run fusion implies that AMPA receptor responses can be lost because of rapid receptor desensitization during a slower initial pulse of glutamate $(\mathrm{He}$ et al., 2006). We previously concluded that this effect occurs in lamprey in 5-HT (Photowala et al., 2006; Schwartz et al., 2007). We now conclude that this causes a train position dependence of vesicle fusion properties that not only applies to how quickly vesicles endocytose and retain FM dyes or Qdots (Harata et al., 2006; Zhang et al., 2007, 2009), but also extends to millisecond aspects of the onset of fusion, to effect efficient AMPAR activation. We propose that signal transduction mechanisms in the presynaptic terminal- $\mathrm{G} \beta \gamma$ - can cause a $\mathrm{Ca}^{2+}$ (Yoon et al., 2007) and therefore state-dependent modification of fusion properties and neurotransmission. It is noteworthy that a protein with a similar WD-40 structure to $\mathrm{G} \beta \gamma$ exists at presynaptic terminals, the R-SNARE-containing protein tomosyn. Its yeast homolog, Sro7, like G $\beta \gamma$ binds to the SNARE region of the SNAP-25 homolog, sec9 (Hattendorf et al., 2007).

\section{References}

Adler EM, Augustine GJ, Duffy SN, Charlton MP (1991) Alien intracellular calcium chelators attenuate neurotransmitter release at the squid giant synapse. J Neurosci 11:1496-1507.

Alford S, Grillner S (1990) CNQX and DNQX block non-NMDA synaptic transmission but not NMDA-evoked locomotion in lamprey spinal cord. Brain Res 506:297-302.

Balaji J, Ryan TA (2007) Single-vesicle imaging reveals that synaptic vesicle exocytosis and endocytosis are coupled by a single stochastic mode. Proc Natl Acad Sci U S A 104:20576-20581.

Biró Z, Hill RH, Grillner S (2006) 5-HT modulation of identified segmental premotor interneurons in the lamprey spinal cord. J Neurophysiol 96:931-935.

Blackmer T, Larsen EC, Takahashi M, Martin TF, Alford S, Hamm HE (2001) G protein betagamma subunit-mediated presynaptic inhibition: regulation of exocytotic fusion downstream of $\mathrm{Ca}^{2+}$ entry. Science 292:293-297.

Blackmer T, Larsen EC, Bartleson C, Kowalchyk JA, Yoon EJ, Preininger AM, Alford S, Hamm HE, Martin TF (2005) G protein betagamma directly regulates SNARE protein fusion machinery for secretory granule exocytosis. Nat Neurosci 8:421-425.

Brocard F, Dubuc R (2003) Differential contribution of reticulospinal cells to the control of locomotion induced by the mesencephalic locomotor region. J Neurophysiol 90:1714-1727.

Brodin L, Grillner S (1986) Effects of magnesium on fictive locomotion induced by activation of $N$-methyl-D-aspartate (NMDA) receptors in the lamprey spinal cord in vitro. Brain Res 380:244-252.

Brodin L, Grillner S, Rovainen CM (1985) N-Methyl-D-aspartate (NMDA), kainate and quisqualate receptors and the generation of fictive locomotion in the lamprey spinal cord. Brain Res 325:302-306.

Brustein E, Rossignol S (1999) Recovery of locomotion after ventral and ventrolateral spinal lesions in the cat. II. Effects of noradrenergic and serotoninergic drugs. J Neurophysiol 81:1513-1530.

Buchanan JT, Grillner S (1987) Newly identified "glutamate interneurons" and their role in locomotion in the lamprey spinal cord. Science 236:312-314.

Buchanan JT, Grillner S (1991) 5-Hydroxytryptamine depresses reticu- lospinal excitatory postsynaptic potentials in motoneurons of the lamprey. Neurosci Lett 122:71-74.

Buchanan JT, Brodin L, Dale N, Grillner S (1987) Reticulospinal neurones activate excitatory amino acid receptors. Brain Res 408:321-325.

Choi S, Klingauf J, Tsien RW (2003) Fusion pore modulation as a presynaptic mechanism contributing to expression of long-term potentiation. Philos Trans R Soc Lond B Biol Sci 358:695-705.

Christenson J, Franck J, Grillner S (1989) Increase in endogenous 5-hydroxytryptamine levels modulates the central network underlying locomotion in the lamprey spinal cord. Neurosci Lett 100:188-192.

Clements JD, Lester RA, Tong G, Jahr CE, Westbrook GL (1992) The time course of glutamate in the synaptic cleft. Science 258:1498-1501.

Doménech T, Beleta J, Palacios JM (1997) Characterization of human serotonin $1 \mathrm{D}$ and $1 \mathrm{~B}$ receptors using [ $\left.{ }^{3} \mathrm{H}\right]-\mathrm{GR}-125743$, a novel radiolabelled serotonin 5HT1D/1B receptor antagonist. Naunyn Schmiedebergs Arch Pharmacol 356:328-334.

Dubuc R, Brocard F, Antri M, Fénelon K, Gariepy JF, Smetana R, Ménard A, LeRay D, Viana Di Prisco G, Pearlstein E, Sirota MG, Derjean D, St-Pierre M, Zielinski B, Auclair F, Veilleux D (2008) Initiation of locomotion in lampreys. Brain Res Rev 57:172-182.

Elhamdani A, Azizi F, Artalejo CR (2006) Double patch clamp reveals that transient fusion (kiss-and-run) is a major mechanism of secretion in calf adrenal chromaffin cells: high calcium shifts the mechanism from kissand-run to complete fusion. J Neurosci 26:3030-3036.

Gerachshenko T, Blackmer T, Yoon EJ, Bartleson C, Hamm HE, Alford S (2005) Gbetagamma acts at the C terminus of SNAP-25 to mediate presynaptic inhibition. Nat Neurosci 8:597-605.

Grillner S, Shik ML (1973) On the descending control of the lumbosacral spinal cord from the "mesencephalic locomotor region." Acta Physiol Scand 87:320-333.

Hammar I, Stecina K, Jankowska E (2007) Differential modulation by monoamine membrane receptor agonists of reticulospinal input to lamina VIII feline spinal commissural interneurons. Eur J Neurosci 26:1205-1212.

Harata NC, Choi S, Pyle JL, Aravanis AM, Tsien RW (2006) Frequencydependent kinetics and prevalence of kiss-and-run and reuse at hippocampal synapses studied with novel quenching methods. Neuron 49:243-256.

Harris-Warrick RM, Cohen AH (1985) Serotonin modulates the central pattern generator for locomotion in the isolated lamprey spinal cord. J Exp Biol 116:27-46.

Hattendorf DA, Andreeva A, Gangar A, Brennwald PJ, Weis WI (2007) Structure of the yeast polarity protein Sro7 reveals a SNARE regulatory mechanism. Nature 446:567-571.

He L, Wu XS, Mohan R, Wu LG (2006) Two modes of fusion pore opening revealed by cell-attached recordings at a synapse. Nature 444:102-105.

Hounsgaard J, Kiehn O (1989) Serotonin-induced bistability of turtle motoneurones caused by a nifedipine-sensitive calcium plateau potential. J Physiol 414:265-282.

Jordan LM, Liu J, Hedlund PB, Akay T, Pearson KG (2008) Descending command systems for the initiation of locomotion in mammals. Brain Res Rev 57:183-191.

Kasicki S, Grillner S, Ohta Y, Dubuc R, Brodin L (1989) Phasic modulation of reticulospinal neurones during fictive locomotion and other types of spinal motor activity in lamprey. Brain Res 484:203-216.

Kay AR, Alfonso A, Alford S, Cline HT, Holgado AM, Sakmann B, Snitsarev VA, Stricker TP, Takahashi M, Wu LG (1999) Imaging synaptic activity in intact brain and slices with FM1-43 in C. elegans, lamprey, and rat. Neuron 24:809-817.

Kozlov A, Kotaleski JH, Aurell E, Grillner S, Lansner A (2001) Modeling of substance $\mathrm{P}$ and 5-HT induced synaptic plasticity in the lamprey spinal CPG: consequences for network pattern generation. J Comput Neurosci 11:183-200.

Liu J, Jordan LM (2005) Stimulation of the parapyramidal region of the neonatal rat brain stem produces locomotor-like activity involving spinal 5-HT7 and 5-HT2A receptors. J Neurophysiol 94:1392-1404.

McLean DL, Masino MA, Koh IY, Lindquist WB, Fetcho JR (2008) Continuous shifts in the active set of spinal interneurons during changes in locomotor speed. Nat Neurosci 11:1419-1429.

Parker D, Grillner S (1999) Activity-dependent metaplasticity of inhibitory and excitatory synaptic transmission in the lamprey spinal cord locomotor network. J Neurosci 19:1647-1656. 
Perrier JF, Delgado-Lezama R (2005) Synaptic release of serotonin induced by stimulation of the raphe nucleus promotes plateau potentials in spinal motoneurons of the adult turtle. J Neurosci 25:7993-7999.

Photowala H, Blackmer T, Schwartz E, Hamm HE, Alford S (2006) G protein betagamma-subunits activated by serotonin mediate presynaptic inhibition by regulating vesicle fusion properties. Proc Natl Acad Sci U S A 103:4281-4286.

Schotland J, Shupliakov O, Wikström M, Brodin L, Srinivasan M, You ZB, Herrera-Marschitz M, Zhang W, Hökfelt T, Grillner S (1995) Control of lamprey locomotor neurons by colocalized monoamine transmitters. Nature 374:266-268.

Schwartz EJ, Gerachshenko T, Alford S (2005) 5-HT prolongs ventral root bursting via presynaptic inhibition of synaptic activity during fictive locomotion in lamprey. J Neurophysiol 93:980-988.

Schwartz EJ, Blackmer T, Gerachshenko T, Alford S (2007) Presynaptic G-protein-coupled receptors regulate synaptic cleft glutamate via transient vesicle fusion. J Neurosci 27:5857-5868.

Shik ML, Severin FV, Orlovsky GN (1969) Control of walking and running by means of electrical stimulation of the mesencephalon. Electroencephalogr Clin Neurophysiol 26:549.

Sigvardt KA, Grillner S, Wallén P, Van Dongen PA (1985) Activation of NMDA receptors elicits fictive locomotion and bistable membrane properties in the lamprey spinal cord. Brain Res 336:390-395.

Sirota MG, Di Prisco GV, Dubuc R (2000) Stimulation of the mesencephalic locomotor region elicits controlled swimming in semi-intact lampreys. Eur J Neurosci 12:4081-4092.

Takahashi M, Freed R, Blackmer T, Alford S (2001) Calcium influxindependent depression of transmitter release by $5-\mathrm{HT}$ at lamprey spinal cord synapses. J Physiol 532:323-336.

Tedford HW, Zamponi GW (2006) Direct G protein modulation of Cav2 calcium channels. Pharmacol Rev 58:837-862.

Tråvén HG, Brodin L, Lansner A, Ekeberg O, Wallén P, Grillner S (1993)
Computer simulations of NMDA and non-NMDA receptor-mediated synaptic drive: sensory and supraspinal modulation of neurons and small networks. J Neurophysiol 70:695-709.

Van Dongen PA, Hökfelt T, Grillner S, Verhofstad AA, Steinbusch HW, Cuello AC, Terenius L (1985) Immunohistochemical demonstration of some putative neurotransmitters in the lamprey spinal cord and spinal ganglia: 5-hydroxytryptamine-, tachykinin-, and neuropeptide-Y-immunoreactive neurons and fibers. J Comp Neurol 234:501-522.

Wallén P, Williams TL (1984) Fictive locomotion in the lamprey spinal cord in vitro compared with swimming in the intact and spinal animal. J Physiol 347:225-239.

Wallén P, Christenson J, Brodin L, Hill R, Lansner A, Grillner S (1989) Mechanisms underlying the serotonergic modulation of the spinal circuitry for locomotion in lamprey. Prog Brain Res 80:321-327; discussion 315-329.

Williams TL (1992) Phase coupling by synaptic spread in chains of coupled neuronal oscillators. Science 258:662-665.

Yoon EJ, Gerachshenko T, Spiegelberg BD, Alford S, Hamm HE (2007) $\mathrm{G} \beta \gamma$ regulates exocytosis by interfering with $\mathrm{Ca}^{2+}$-dependent binding of synaptotagmin to the SNARE complex. Mol Pharmacol 72:1210-1219.

Zelenin PV, Grillner S, Orlovsky GN, Deliagina TG (2001) Heterogeneity of the population of command neurons in the lamprey. J Neurosci 21:7793-7803.

Zhang Q, Cao YQ, Tsien RW (2007) Quantum dots provide an optical signal specific to full collapse fusion of synaptic vesicles. Proc Natl Acad Sci U S A 104:17843-17848.

Zhang Q, Li Y, Tsien RW (2009) The dynamic control of kiss-and-run and vesicular reuse probed with single nanoparticles. Science 323:1448-1453.

Zhong G, Díaz-Ríos M, Harris-Warrick RM (2006) Serotonin modulates the properties of ascending commissural interneurons in the neonatal mouse spinal cord. J Neurophysiol 95:1545-1555. 